\title{
Potential Synergistic Action of Liquid Olive Fruit Polyphenol Extract with Aqueous Extracts of Solid Wastes of Pomegranate or/and Orange Juice Industry as Organic Phyto-protective Agents against Important Plant Pathogens - Part 1 (in vitro Studies)
}

\author{
Stefanos Leontopoulos ${ }^{1}$, Chrisanthi Mitsagga ${ }^{2}$, Ioannis Giavasis ${ }^{2}$, Christina Papaioannou ${ }^{1}$, \\ Ioannis Vasilakoglou ${ }^{1}$, Konstantinos Petrotos ${ }^{1}$ \\ ${ }^{1}$ Department of Agrotechnology, Laboratory of Food and Biosystems Engineering, University of Thessaly, Greece \\ ${ }^{2}$ Department of Food Technology, Laboratory of Food Microbiology, University of Thessaly, Greece
}

Received August 10, 2020; Revised September 8, 2020; Accepted October 19, 2020

\section{Cite This Paper in the following Citation Styles}

(a): [1] Stefanos Leontopoulos, Chrisanthi Mitsagga, Ioannis Giavasis, Christina Papaioannou, Ioannis Vasilakoglou, Konstantinos Petrotos , "Potential Synergistic Action of Liquid Olive Fruit Polyphenol Extract with Aqueous Extracts of Solid Wastes of Pomegranate or/and Orange Juice Industry as Organic Phyto-protective Agents against Important Plant Pathogens - Part 1 (in vitro Studies)," Universal Journal of Agricultural Research, Vol. 8, No. 6, pp. 202 - 222, 2020. DOI: 10.13189/ujar.2020.080602.

(b): Stefanos Leontopoulos, Chrisanthi Mitsagga, Ioannis Giavasis, Christina Papaioannou, Ioannis Vasilakoglou, Konstantinos Petrotos (2020). Potential Synergistic Action of Liquid Olive Fruit Polyphenol Extract with Aqueous Extracts of Solid Wastes of Pomegranate or/and Orange Juice Industry as Organic Phyto-protective Agents against Important Plant Pathogens - Part 1 (in vitro Studies). Universal Journal of Agricultural Research, 8(6), 202 - 222. DOI: 10.13189/ujar.2020.080602.

Copyright@2020 by authors, all rights reserved. Authors agree that this article remains permanently open access under the terms of the Creative Commons Attribution License 4.0 International License

\begin{abstract}
In this research study potential synergistic action of aqueous extracts of olive-pomegranate-orange fruits isolated by microwave assisted extraction were investigated as biocontrol agents against several plant pathogenic fungi. The aim of the research study was the production of mixed liquid extracts to be used as natural phytoprotective agents in organic farming. The results proved that the use of $100 \%$-pure olive fruit polyphenol extract affected the mycelium growth of $B$. cinerea, $V$. dahliae, $R$. solani, E. lata, M. laxa, $P$. lycopersici and $P$. punicae. However, it did not affect the mycelium growth of F. oxysporum f. sp., lycopersici, A. niger, and G. graminis. Moreover, pomegranate polyphenol extract at $100 \%$ concentration inhibited mycelium growth of $B$. cinerea. Various olive-pomegranate-orange polyphenol aqueous extract combinations may be used in order to control the mycelium growth of the majority of the tested microorganisms. However, the use of any combination and
\end{abstract}

concentrations of the tested samples (1-72) did not affect the mycelium growth of $F$. oxysporum f. sp., lycopersici, A. niger, and G. graminis thus, their use as biological control agent is not recommended. According to the findings of the present research, it can be suggested that the olive fruit polyphenol extract be used as potential biocontrol agent, in order to stimulate mycelium growth of various plant pathogenic fungi.

Keywords Polyphenols, Pomegramate, Orange, Olive Fruit Extracts, Biocontrol, Plant Diseases

\section{Introduction}

The increase in the human population as a result of the improvement of the standard of living results the intensification of food processing and the problematic 
disposal of organic-agri-food waste in the environment. The agri-food processing sector, particularly in the Mediterranean region, produces large volumes of waste with a high organic load, rich in polyphenols. By using appropriate methods of decontamination and extraction, these wastes can be used by reducing the volume of waste material, or by producing high value-added products that can benefit consumers and the environment.

Usually, by-products of agri-food processing have high management costs and may contaminate the environment when disposed out without any treatment. However, these by-products often hide a small "treasure", since they contain rich amounts of natural antioxidant, antimicrobial and bioactive substances that can be isolated and recovered from these wastes. The aforementioned approach is also an EU guideline under the term of bio-refinery which means the gradual full utilization of solid waste for the production of a range of valuable materials. This approach leads to a reduction in the carbon footprint of solid waste due to its full utilization and therefore its re-introduction into the food chain either directly as antimicrobial or antioxidant food additives or indirectly as eco-plant protection materials. In addition, the synergy of the produced bio-functional substances may further increase their potency especially in microbiostatic or microbicidal activity according to the well-known theory of multiple barriers [1].

\subsection{Agricultural Wastes Used in This Study}

In this study, agricultural wastes by three plant species were examined for their antimicrobial potential activity. These wastes were aqueous microwave assisted isolates extracted by olive fruit, pomegranate and orange peels.

The olive tree (Olea europaea) cultivated worldwide on approximately 9.5 million hectares with more than 900 million trees [2] for its fruits that are consumed as edible or crushed as oil [3]. However, the main cultivated area of olive trees is located in Mediterranean basin. The olive oil sector has become particularly important contributing to both the National economy and the nutrition of the population by providing consumers with high nutritional value products such as olive oil. More specific, the Greek olive oil industry is one of the most dynamic growing sectors actively participating in boosting annual GDP. Thus, the increasing demand for olive oil has led to the exploration and exploitation of larger quantities, resulting in large amounts of wastes disposal. This problematic disposal of liquid and solid waste results from this activity not only in Greece but also in other Mediterranean olive oil producing countries, posing a significant environmental problem. Large olive oil industries but mainly small scattered, low-cost, family-owned olive-oil plants (mills) that were already operating in the area are considered to be the main ones responsible for the environmental damage caused by uncontrolled waste discharges. Although the competition in the industry between the various companies is intense, any activity focuses mainly on maximizing production rather than environmental protection and waste management. An obvious solution to this problem is believed to be the use of these wastes which are polyphenolated substances in various applications as food additives, plant protection products and elsewhere giving added value to the disposed product.

The orange tree (Citrus sinensis) cultivated worldwide in subtropical and tropical climates belongs to family Rutaceae producing fruits that can be eaten fresh, or processed for its juice or fragrant peel. Worldwide production in 2017 arises in 73 million tons of oranges with Brazil producing $24 \%$ of the world total, followed by China and India [4].

Pomegranate (Punica granatum) is a fruit with worldwide distribution [5]. Although the evidence for the use of polyphenolic substances is very promising, extensive studies are needed to fully understand its contribution to human health before setting up its regular consumption [6]. The bioavailability, bio-distribution and metabolism of the major bioactive compounds present in pomegranates, such as phenolic acids, flavonoids and tannins have been studied by many authors [7-19].

During the juicing process large quantities of bark and seeds (accounting for about $50 \%$ of total weight) are disposed of as waste [20]. Discarded pomegranate peel and juice contains many phenolic substances and particularly flavonoids but, unlike pomegranate juice, is a by-product and is discarded in the environment.

\subsection{Natural Secondary Metabolites as Plant Protective Material}

Several physiological functions such as growth, reproduction, coloration, resistance to pathogens, and generally to plant acclimatization in a growing environment depended by the production of secondary metabolites produced by plants in very small quantities (less than 1\% dry weight) [21-33]. The production of these secondary metabolites depends primarily on the growth phase and maturity of the plants [34,35]. Today, more than 100,000 secondary metabolites are known to be involved in the plant protection system [36]. Some of these secondary metabolites apparently act as defense mechanisms against germs [37-41], or as plant antagonists [42,43]. Among the secondary metabolites, phenolic compounds such as flavonoids and hydroxycinnamic acid derivatives are found in almost all plant species [44] and are of great importance since most of them are used for defense functions exhibiting antimicrobial properties [45-47], against fungi [48-50] and viruses [42].

However, in a recent study [29], secondary metabolites not only play an important role in the interactions between plants and microbes but are also used by humans in modern and traditional industries such as medicines, perfumes, pharmaceuticals, agrochemicals, colors, biopesticides and food additives [38,51].

The interest in the use of polyphenolic substances as plant protection products has been due to decades of 
204 Potential Synergistic Action of Liquid Olive Fruit Polyphenol Extract with Aqueous Extracts of Solid Wastes of Pomegranate or/and Orange Juice Industry as Organic Phyto-protective Agents against Important Plant Pathogens - Part 1 (in vitro Studies)

uninterrupted and indiscriminate use of synthetic pesticides and fungicides which have not only led to the development of resistant strains in microorganisms, but have also resulted in the presence of toxic residues in the soil [52] and in crops [53,54] used for human consumption and therefore substantially affecting the quality of human health and the environment [55-57].

The management and utilization of waste of agricultural industries such as olive oil mills and juice industries is important for the protection of the environment and water resources. Recording the problem and identifying potential uses of wastes as plant protection products, as food additives for human consumption and as soil conditioners are believed to help the utmost in this regard. Thus, the aim of the research study was the production of mixed liquid extracts to be used as natural phytoprotective agents in organic farming. The assessment of different concentrations and mixtures of polyphenols from olive oil wastes-orange and pomegranate as plant protection materials against economically important plant pathogenic fungi in in vitro tests is the main research area of this research work. Disk diffusion assay, well diffusion assay and MIC/MLC of several economic important soil borne and foliar fungal pathogens were examined in order to assess the effectiveness of these polyphenolic mixtures.

\section{Materials and Methods}

The in vitro antimicrobial activity of polyphenols was evaluated in a number of phytopathogenic fungi such as the fungus Verticillium dahliae which together with Fusarium oxysporum f.sp. lycopersici cause stenosis on tomato vascular tissues, Botrytis cinerea (usually known as "grey mould" or "gray mold") a necrotrophic fungus that affects many plant species, although its most notable hosts may be wine grapes, Aspergillus niger, the most common species of the genus Aspergillus which causes a disease called "black mold" on certain fruits and vegetables and produces important potent mycotoxins called ochratoxins, Gaeumanomyces graminis a plant pathogen that produces extensive damage on the sheath of rice, causing black spots, Rhizoctonia solani a wide host range and worldwide distribution soil borne pathogen that attacks its hosts when they are in their early stages of development, such as seeds and seedlings, Eutypa lata and important plant pathogen on vines, Monillia laxa a plant pathogen that is responsible for the brown rot blossom blight disease that infects many different types of stone fruit trees, Pyrenochaeta lycopersici, which infects and causes damage to members of the families of Solanaceae and Cucurbitaceae causing brown lesions on the surface of medium roots and Phoma punicae a common soil borne pathogen. All fungal microorganisms used in this study were obtained from the Benaki Phytopathological Institute (B.F.I.) in Athens Greece. The plant pathogens, their code and the source of collection are listed in the following Table 1.
Table 1. Used fungal species in bio-assays

\begin{tabular}{ccc}
\hline Fungal pathogen & Code & Source of Collection \\
\hline Gaeumanomyces graminis & 1394 & B.F.I. \\
Monillia laxa & 1387 & B.F.I. \\
Verticillium dahliae & 2509 & B.F.I. \\
Aspergillus niger & 1970 & B.F.I. \\
Botrytis cinerea & 1948 & B.F.I. \\
Pyrenochaeta lycopersici & 2587 & B.F.I. \\
Eutypa lata & 1367 & B.F.I. \\
Rhizoctonia solani & 2531 & B.F.I. \\
Phoma punicae & 2663 & B.F.I. \\
Fusarium oxysporum f.sp. & 2550 & B.F.I. \\
lycopersici & &
\end{tabular}

The potential synergistic action and antimicrobial activity of liquid olive fruit polyphenol extract with aqueous extracts of solid wastes of pomegranate or/and orange juice industry against fungal phytopathogenic species were examined by Well diffusion assay. In a lateral stage Minimum Inhibitory Concentration (MIC) and Minimum Lethal Concentration (MLC) was used in order to observe the potency of different mixtures and concentrations of the examined polyphenols against important phytopathogenic fungi and to determine the major effect in inhibiting the mycelium growth.

In order to maintain the cultures for longer period parts of hyphae of plant pathogens from the initial medium were placed in test tubes containing nutrient medium agar (PDA) and stored in the refrigerator at $3^{\circ} \mathrm{C}$. Experiments on the potential synergistic action of liquid olive fruit polyphenol extract with aqueous extracts of solid wastes of pomegranate or/and orange juice industry as organic phyto-protective agents against important plant pathogens was conducted using sections and spores of this stored material. The concentrations and combinations of liquid olive fruit pomegranate and orange extracts used were as follows in Table 2.

Subsequently, the liquid solutions were placed in sterile commercial plastic containers, numbered from 1 to 68 (which are also the samples) and frozen at $-23.3^{\circ} \mathrm{C}$. Whenever needed, a small amount of the samples were used in order to examine their antifungal activity against important plant pathogenic microorganisms. Before any application approximately $20 \mathrm{ml}$ of the solutions (1-72) were filtered with plain filter paper to retain possible solid residues, $\mathrm{pH}$ and Brix were measured and then, $15 \mathrm{ml}$ of each solution was transferred to glass tubes and heat treated in the sterilization oven at $100^{\circ} \mathrm{C}$ for 20 minutes. The $\mathrm{pH}$ of the liquid growth medium was measured in triplicate (using a HANNA pH 210 pHmeter). The resulting heat-treated solutions were used in the experimental procedure.

For the development of phytopathogenic fungi, a MRD and PDA nutrient substrate was used. This nutrient substrate was prepared as follows: $500 \mathrm{ml}$ of deionized water and $19.5 \mathrm{~g}$ of PDA powder was placed in a $500 \mathrm{ml}$ flask. The contents were stirred for approximately 30 minutes to dissolve the PDA powder in deionized water. The solution was then placed in the sterilization oven where it was sterilized at $121^{\circ} \mathrm{C}$ for 20 minutes. The 
solution is placed in Petri dishes under aseptic conditions in a filament chamber. The material of the Petri dishes (about $20 \mathrm{ml}$ ) is allowed to stand in the filament chamber.

A PDB (Oxoid) nutrient substrate was used to prepare the nutrient substrate used in the MIC and MLC experiments as follows: $24 \mathrm{~g}$ of PDB powder was dissolved in $1 \mathrm{ml}$ containing deionized water. The various concentrations used were incorporated into this substrate.

Seventy two (72) different samples and phytopathogenic microorganisms mixed with PDA nutrient were used to examine the effect of different concentrations and mixtures of the olive, pomegranate and orange extracts tested. The concentrations and mixtures of the 72 solutions are reported in Table 2. Before PDA application to the Petri dishes, $1.5 \mathrm{ml}$ of the solutions 1-72 were placed in them. Then $20 \mathrm{ml}$ of PDA nutrient substrate applied to each plate with stirring simultaneously to incorporate the solution into the nutrient substrate. The plates were then allowed to stand for about 30 minutes to stabilize the nutrient substrates. Finally, a small well (like a well) was then centrifuged in the center of the plate with the sterilized nutrient substrate, in which $25 \mu \mathrm{l}$ of the test fungus was poured. The number of replicates per treatment was 4 . Measurements were taken on the last day of incubation by means of mycelium growth in $\mathrm{mm}$.

Table 2. Concentrations and combinations of the examined extracts

\begin{tabular}{|c|c|c|c|c|c|c|c|}
\hline $\begin{array}{c}\text { Number of } \\
\text { sample }\end{array}$ & Olive fruit & Pomegranate & Orange & $\begin{array}{r}\text { Number } \\
\text { of sample }\end{array}$ & $\begin{array}{l}\text { Olive } \\
\text { fruit }\end{array}$ & Pomegranate & Orange \\
\hline 1 & 90 & 10 & 0 & 37 & 80 & 10 & 10 \\
\hline 2 & 80 & 20 & 0 & 38 & 90 & 5 & 5 \\
\hline 3 & 70 & 30 & 0 & 39 & 0 & 30 & 70 \\
\hline 4 & 60 & 40 & 0 & 40 & 10 & 27 & 63 \\
\hline 5 & 50 & 50 & 0 & 41 & 20 & 24 & 56 \\
\hline 6 & 40 & 60 & 0 & 42 & 30 & 21 & 49 \\
\hline 7 & 30 & 70 & 0 & 43 & 40 & 18 & 42 \\
\hline 8 & 20 & 80 & 0 & 44 & 50 & 15 & 35 \\
\hline 9 & 10 & 90 & 0 & 45 & 60 & 12 & 28 \\
\hline 10 & 90 & 0 & 10 & 46 & 70 & 9 & 21 \\
\hline 11 & 80 & 0 & 20 & 47 & 80 & 6 & 14 \\
\hline 12 & 70 & 0 & 30 & 48 & 90 & 3 & 7 \\
\hline 13 & 60 & 0 & 40 & 49 & 0 & 60 & 40 \\
\hline 14 & 50 & 0 & 50 & 50 & 10 & 54 & 36 \\
\hline 15 & 40 & 0 & 60 & 51 & 20 & 48 & 32 \\
\hline 16 & 30 & 0 & 70 & 52 & 30 & 42 & 28 \\
\hline 17 & 20 & 0 & 80 & 53 & 40 & 36 & 24 \\
\hline 18 & 10 & 0 & 90 & 54 & 50 & 30 & 20 \\
\hline 19 & 0 & 70 & 30 & 55 & 60 & 24 & 16 \\
\hline 20 & 10 & 63 & 27 & 56 & 70 & 18 & 12 \\
\hline 21 & 20 & 56 & 24 & 57 & 80 & 12 & 8 \\
\hline 22 & 30 & 49 & 21 & 58 & 90 & 6 & 4 \\
\hline 23 & 40 & 42 & 18 & 59 & 0 & 40 & 60 \\
\hline 24 & 50 & 35 & 15 & 60 & 10 & 36 & 54 \\
\hline 25 & 60 & 28 & 12 & 61 & 20 & 32 & 48 \\
\hline 26 & 70 & 21 & 9 & 62 & 30 & 28 & 42 \\
\hline 27 & 80 & 14 & 6 & 63 & 40 & 24 & 36 \\
\hline 28 & 90 & 7 & 3 & 64 & 50 & 20 & 30 \\
\hline 29 & 0 & 50 & 50 & 65 & 60 & 16 & 24 \\
\hline 30 & 10 & 45 & 45 & 66 & 70 & 12 & 18 \\
\hline 31 & 20 & 40 & 40 & 67 & 80 & 8 & 12 \\
\hline 32 & 30 & 35 & 35 & 68 & 90 & 4 & 6 \\
\hline 33 & 40 & 30 & 30 & 69 & \multicolumn{3}{|c|}{ Only fungus (control) } \\
\hline 34 & 50 & 25 & 25 & 70 & 100 & 0 & 0 \\
\hline 35 & 60 & 20 & 20 & 71 & 0 & 100 & 0 \\
\hline 36 & 70 & 15 & 15 & 72 & 0 & 0 & 100 \\
\hline
\end{tabular}


206 Potential Synergistic Action of Liquid Olive Fruit Polyphenol Extract with Aqueous Extracts of Solid Wastes of Pomegranate or/and Orange Juice Industry as Organic Phyto-protective Agents against Important Plant Pathogens - Part 1 (in vitro Studies)

The treated petri dishes were incubated at $28^{\circ} \mathrm{C}$ for up to various days depending on the mycelium growth of each fungal species. More specific last mycelium growth measurement for $F$. oxysporum f.sp., lycopersici and $G$. graminis was made after 7 days of incubation at $28^{\circ} \mathrm{C}$, for $V$. dahliae after 16 days, for $B$. cinerea after 18 days, for $A$. niger after 5 days, for $R$. solani after 17 days, for $E$. lata after 11 days and for M. laxa, P. lycopersici and P. punicae after 14 days. Unfortunately, there was no mycelium growth even in the control for the fungal species $P$. expansum, A. alternata and S. sclerotiorum possibly due to a stress factor on which the strains of the microorganisms were exposed.

The following concentrations were applied to the method of determination of the minimum inhibitory / lethal concentration MIC / MLC: 2.5\%, 5\%, 7.5\% In this method, sterile test tubes containing $10 \mathrm{ml}$ of PDB substrate were prepared. Subsequently, the following amounts of samples $1,10,11,28,46,48,57,58,67$ and 70 were added to the fluidized substrates which were determined to require further transduction. To achieve the final volume of the different concentrations, the following amounts of polyphenol were then applied until $10 \mathrm{ml}$ of the test tube was filled. Then the test tubes with the nutrient substrate and the corresponding polyphenol sample $(1,10,11,28,46$, $48,57,58,67$ and 70 ) were sterilized at $100^{\circ} \mathrm{C}$ for 20 minutes. The bioassays concerned plant pathogenic fungi with inhibitory effects on the samples. These fungi were the following: $V$. dahliae, B. cinerea, E. lata, M. laxa, $R$. solani, P. lycopersici, P. punicae, F. oxysporum f.sp. lycopersici, A. niger and G. graminis. Inoculation of the test tubes was followed by streak of 10 plant pathogenic fungi $(0.1 \mathrm{ml}$ of each phytopathogenic fungal suspension), separately for each test tube. The test tube containing spores and mycelium of each fungus was placed in the Vortex apparatus for stirring before each use. The test tubes with the fungi were incubated at $22{ }^{\circ} \mathrm{C}$ for 7 days. After completion of the incubation, the results concerning the growth of mycelium in the solution (on the surface or bottom of the test tube) were recorded. Test tubes in which the pathogenic fungal mycelium had grown showed that the amount of liquid polyphenol (samples 1, 10, 11, 28, 46, 48, 57, 58, 67 and 70) was not sufficient to inhibit the growth of microorganisms, were labeled as "positive". While test tubes that did not show any mycelial growth of the tested fungus were considered to have inhibited its growth ("negative").

In order, to determine whether these amounts of polyphenols in the samples $(1,10,11,28,46,48,57,58,67$, and 70) were capable of causing, in addition to inhibiting the fungi, lethal effect, tubes containing $5 \mathrm{ml}$ of MRD were added with $0.1 \mathrm{ml}$ of the sample to the test tube in which the fungus had not grown at all. The amount of this test tube was stirred well in Vortex and incubated at $27^{\circ} \mathrm{C}$ for 48 hours. In those tubes where it was observed mycelium growth, it was concluded that the amount of liquid polyphenol had simply only inhibited the growth of the fungus without killing it. In contrast in test tubes where observed no-growth of mycelium, the minimal amount of polyphenol added was also the lethal concentration.

\section{Statistical Analysis}

A randomized complete block experiment design was selected for the study. Data are expressed as the means of 4 measurements. Statistical differences among the mean values were detected by ANOVA. Tukey's pairwise comparison test, and Dunkan's test was used in order to group the examined samples at 0.05 level. SPSS software was used as a tool to perform the statistical analyses.

\section{Results}

\subsection{Results on $\mathrm{pH}$ and Brix Measurements}

$\mathrm{pH}$ measurements ranged from 6.05 in sample 72 with orange to 4.41 in sample number 71 with pomegranate. However, values in the other mixing samples were usually in the range of 4.8-5.0. Similarly, the brix ranged from 2.3 to 2.6 in sample 71 and 72 containing pomegranate and orange respectively to 23.6 in sample 70 containing olive polyphenol.

\subsection{Results on Mycelium Growth Assay}

\subsubsection{Potential synergistic action on F. oxysporum f.sp., lycopersici}

According to Figure 1, samples 70, 47, 10 and 38 that were contained up to $90 \%$ olive fruit polyphenol exhibited the greatest inhibitory activity against mycelial growth of $F$. oxysporum during the first 7 days of incubation. Similarly, samples 28 and 68 containing up to $90 \%$ olive polyphenol mixed with pomegranate and orange also reduced the growth of $F$. oxysporum mycelium. All of the samples mentioned above differed statistically significantly from the control (69) containing only the phytopathogenic fungus. It is noteworthy that there was no statistically significant difference between control 69 (fungus only) with the extracts 71 (100\% pomegranate peel extract), 72 (100\% orange peel extract), $43 \quad(40 \%$ olive- $18 \%$ pomegranate- $42 \%$ orange mix), 59 (40\% pomegranate$70 \%$ orange mix), 16 (30\% olive-70\% orange mix), 63 (40 olive- $20 \%$ pomegranate- $36 \%$ orange) 15 (40\% olive- $60 \%$ orange), 39 (30\% pomegranate-70\% orange), 19 (70\% pomegranate- $30 \% \quad$ orange $), \quad 40 \quad(10 \% \quad$ olive- $27 \%$ pomegranate- $63 \%$ orange), 17 (20\% olive- $80 \%$ orange), 60 (10\% olive-36\% pomegranate-54\% orange), 18 (10\% olive- $90 \%$ orange), 42 (30\% olive- $21 \%$ pomegranate- $49 \%$ orange) and 44 (50\% Elia-15\% pomegranate-35\% orange). Inhibition of the mycelium growth of $F$. oxysporum 
mycelium after 7 days of incubation was observed in more samples than in 3 days before. This suggests that the $F$. oxysporum fungus may exceed the initial shock in expression of the tested samples experienced during the first days of incubation.

\subsubsection{Potential synergistic action on $V$. dahliae}

According to Figure 2 the control sample 69 containing only mycelium and spores of $V$. dahliae was statistically different from all other samples. In the samples containing $70-30 \%$ and $50-50 \%$ percentage of pomegranate and orange polyphenol extract, growth of mycelium was observed (samples 29, 30, 19, 39). Similar results were observed in samples 20, 40, 50, 60 where olive fruit extract was up to $10 \%$. Control samples 71 and 72 (pomegranate and orange polyphenol extract) showed also mycelium growth of $V$. dahliae after 16 days of incubation at $28^{\circ} \mathrm{C}$. Samples 31 and 61 containing a mixture of $20 \%$ olive polyphenol and pomegranate-orange in a ratio of $1: 1$ and $1: 1.5$, respectively, whereas at the initial measurement at 4 days of incubation no growth of mycelium was observed after 16 days of incubation. It was generally observed that the higher the amount of olive fruit extract contained in the mixing of the samples, the more effective the inhibitory effect of the mixtures on the $V$. dahliae fungus was.

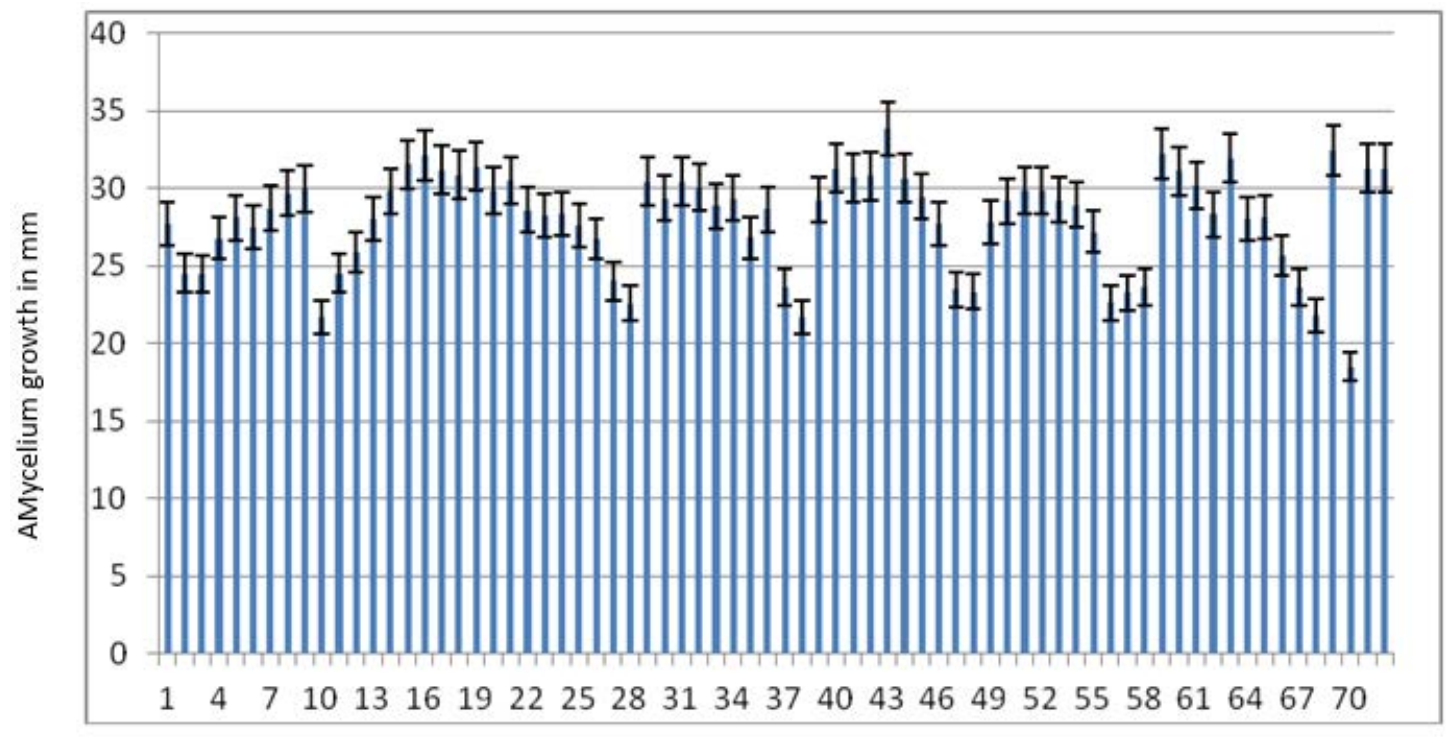

Sample number

Figure 1. Mycelium growth of $F$. oxysporum 7 days after incubation at $28^{\circ} \mathrm{C}$.

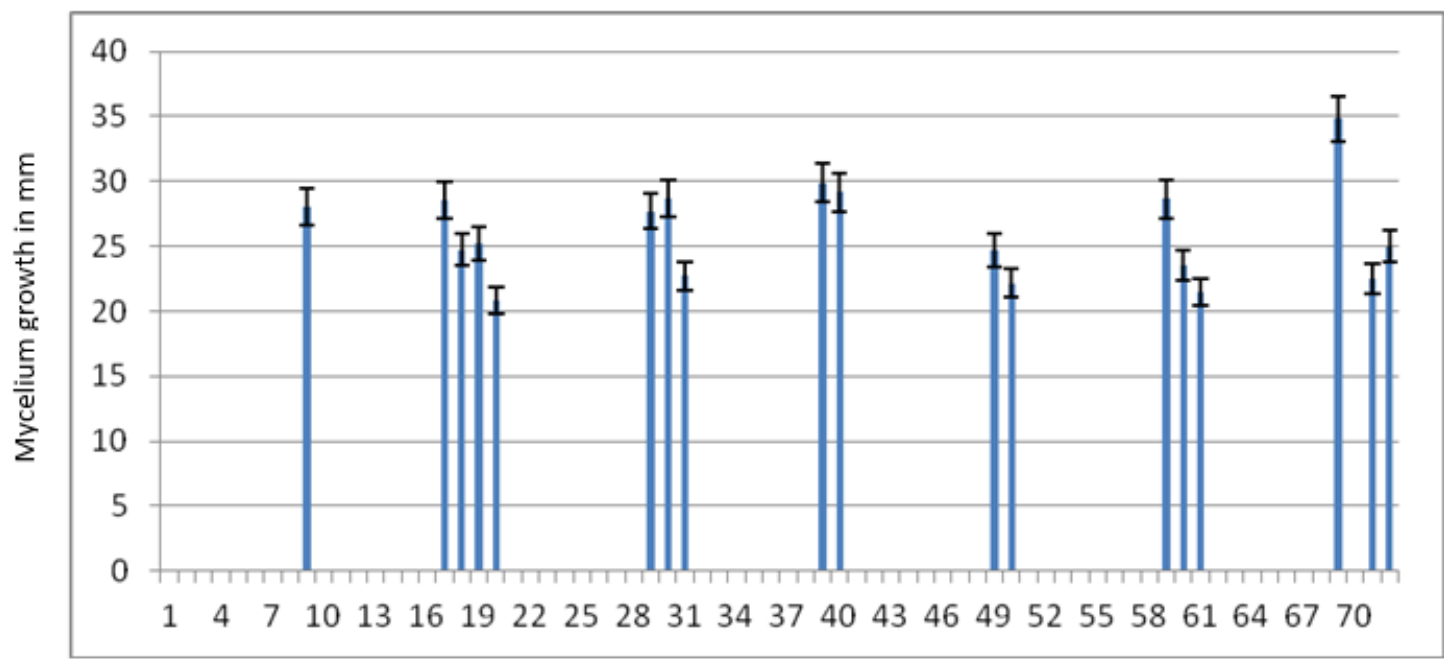

Sample number

Figure 2. Mycelium growth of $V$. dahliae 16 days after incubation at $28^{\circ} \mathrm{C}$. 
208 Potential Synergistic Action of Liquid Olive Fruit Polyphenol Extract with Aqueous Extracts of Solid Wastes of Pomegranate or/and Orange Juice Industry as Organic Phyto-protective Agents against Important Plant Pathogens - Part 1 (in vitro Studies)

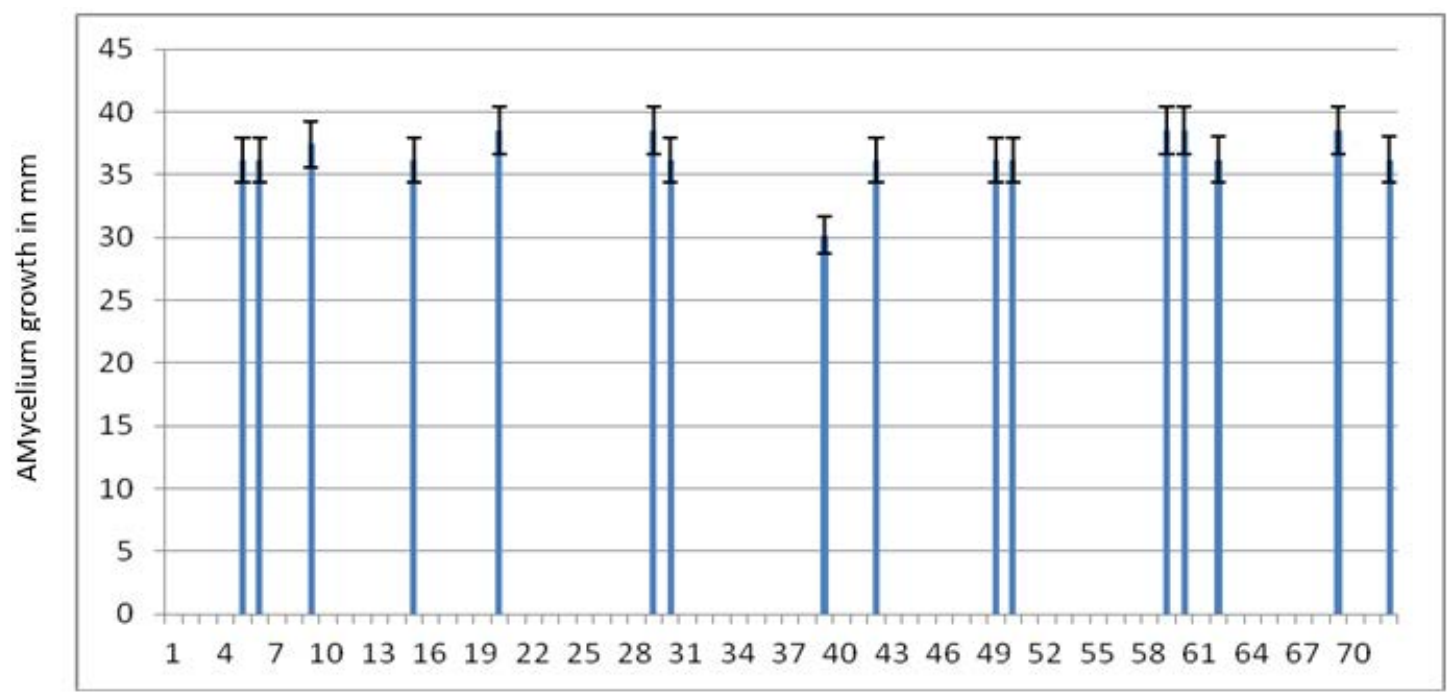

Sample number

Figure 3. Mycelium growth of B.cinerea 18 days after incubation at $28^{\circ} \mathrm{C}$.

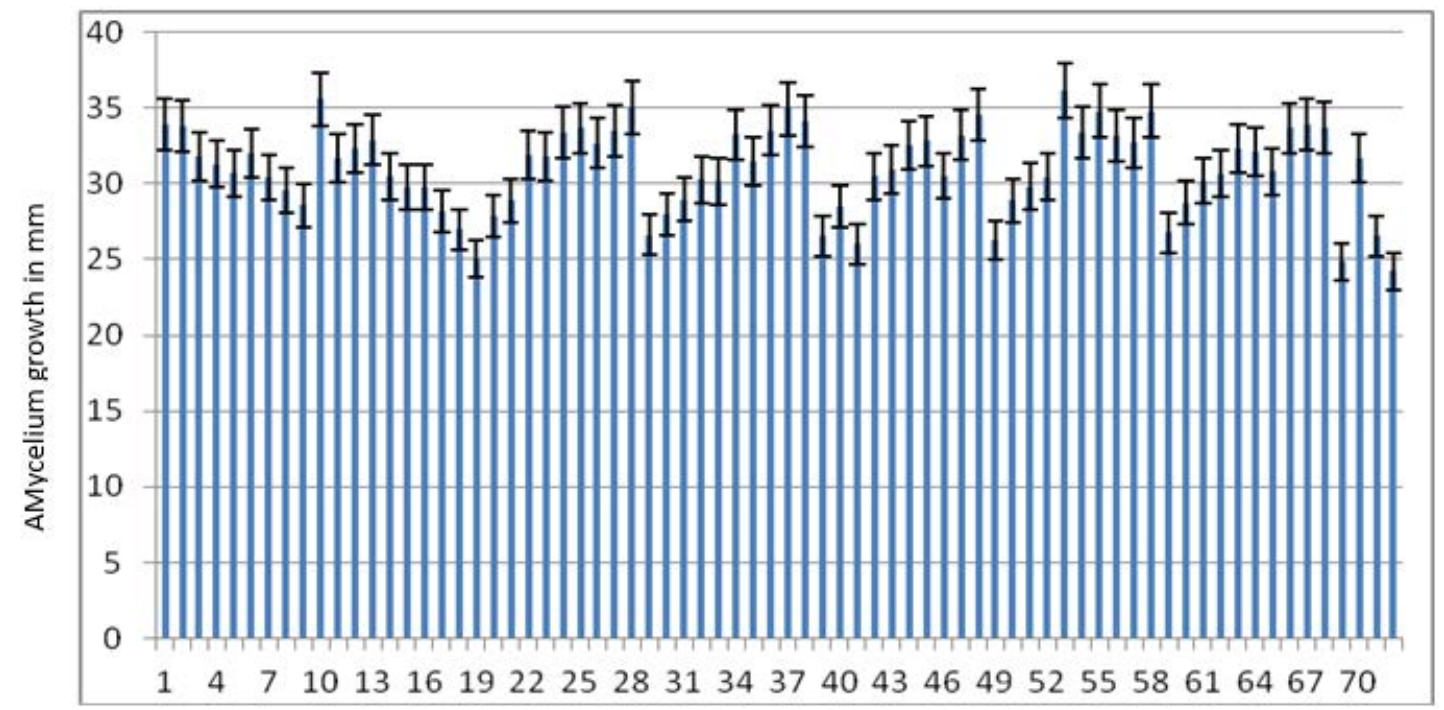

Sample number

Figure 4. Mycelium growth of $G$. graminis 7 days after incubation at $28^{\circ} \mathrm{C}$.

\subsubsection{Potential synergistic action on $B$. cinerea}

According to Figure 3 after 18 days of incubation at $28^{\circ} \mathrm{C}$, the growth of $B$. cinerea was such that it covered the whole Petri dish. No statistically significant differences were observed between samples 69, 20, 29, 59, 60, 5, 6, 9, $15,30,42,49,50,60$ and 72 . Slower mycelium growth was observed in the sample 39 (30\% pomegranate-70\% orange). It was generally observed that the higher the amount of olive polyphenol contained in the mixing of the samples, the more effective the inhibitory effect of the mixtures on the $B$. cinerea was. However, the combination of olive-orange mix even at high olive concentrations (40\%) shows that it does not affect the growth of $B$. cinerea. However, there was no mycelium growth in the rest of the samples.

\subsubsection{Potential synergistic action on $A$. niger}

The growth of $A$. niger $\mathrm{f}$ after 5 days of incubation was not inhibited by any of the concentrations and mixtures of the olive-pomegranate and orange extracts used in this study. A. niger colonized the entire Petri dish very fast. Both the control sample 69 containing only mycelium and spores of the fungus and the other samples were normally grown and no statistically significant difference were observed. A. niger is considered to be one of the most competitive microorganisms in nature and the control and restriction of both mycelium and its conidia is particularly difficult.

\subsubsection{Potential synergistic action on G. graminis}

According to Figure 4 mycelium growth of $G$. graminis after 7 days of incubation was not inhibited by any of the concentrations and mixes of the olive-pomegranate and orange extracts used in this study. G. graminis colonized 
the Petri dish very fast. It was observed that in sample 72 (100\% orange) the mycelium growth was slightly smaller, but not enough to say that there was some action of the extracts used. G. graminis is considered to be one of the most competitive microorganisms in nature. Limitation of both mycelium and conidia is particularly difficult. It is worth to be mentioned that higher the concentration of olive polyphenol in the sample (eg. samples 28 , 38, etc.) the more intense the growth of the mycelium.

\subsubsection{Potential synergistic action on $R$. solani}

According to Figure 5 mycelium of $R$. solani (sample 69) covered the entire surface of the Petri dish after 17 days of incubation at $28^{\circ} \mathrm{C}$. Beside control sample (69) maximum mycelium growth was observed in samples $72.71,59,52$, $51,50,49,42,41,39,7,5,32,31,30,29,22,21,20,19,18$, $17,15,9$, and 8 where according to Tukey's test did not differ statistically significantly from each other. In contrast, no growth of mycelium was observed in samples 1, (90\% olive-10\% pomegranate) 10 (90\% olive- $10 \%$ orange), 11 ( $80 \%$ olive- $20 \%$ orange), 13 (60\% olive- $40 \%$ orange), 24 (50\% olive-35\% pomegranate-15\% orange), 27 (80\% olive-14\% pomegranate-6\% orange), 28 (90\% olive-7\% pomegranate-3\% orange), $34 \quad(50 \% \quad$ olive- $25 \%$ pomegranate-25\% $\quad$ orange), $36 \quad(70 \% \quad$ olive- $15 \%$ pomegranate-15\% $\quad$ orange), $\quad 37 \quad(80 \% \quad$ olive- $10 \%$ pomegranate-10\% $\quad$ orange), $\quad 38 \quad(90 \%$ olive-5\% pomegranate-5\% $\quad$ orange), $\quad 47 \quad(80 \% \quad$ olive-6\% pomegranate-14\% $\quad$ orange), $\quad 48 \quad(90 \%$ olive-3\% pomegranate- $7 \%$ orange), $53 \quad(40 \% \quad$ olive-36\% pomegranate-24\% $\quad$ orange $), \quad 57 \quad(80 \% \quad$ olive- $12 \%$ pomegranate-8\% orange), $58 \quad(90 \%$ olive-6\% pomegranate- $4 \%$ orange), $65 \quad(60 \%$ olive- $16 \%$ pomegranate- 24 orange), 67 (80 \% olive- $8 \%$ rose I-12\% orange), 68 (90\% olive- $4 \%$ pomegranate- $6 \%$ orange), and 70 (100\% olive), which generally contained olive fruit polyphenols in the proportion of $80-90 \%$. From the above treatments the samples 13 (60\% olive- $40 \%$ orange), 29 (50\% olive-35\% pomegranate- $15 \%$ orange), 34 (50\% olive-25\% pomegranate- $25 \%$ orange), 53 ( $40 \%$ olive- $36 \%$ pomegranate- $24 \%$ orange) and 65 (60\% olive- $16 \%$ pomegranate- $24 \%$ orange) are in great interests since they are mixtures of olive-pomegranate and orange extracts. Furthermore, after 17 days of incubation at $28^{\circ} \mathrm{C}$, no mycelium growth was observed in those samples in which olive fruit polyphenol alone was applied at a concentration $>80-90 \%$. On the contrary, mycelium growth was observed in 12 new treatments, where in the previous measurement (8 days) this had not developed. Such treatments are samples $4,12,25,26,35,44,45,46,54,55$, 56 and 66 indicating that any inhibitory activity of the polyphenols mixtures is affected by the exposure period to the microorganisms. The longer the time elapsed from the day the microorganisms are inoculated into the polyphenols solution, the lower their activity effect. Limited mycelial growth (less than $10 \mathrm{~mm}$ ) was observed in the samples 12 ( $70 \%$ olive- $30 \%$ orange), 55 (60\% olive$20 \%$ pomegranate- $16 \%$ orange), 46 (70\% olive- $9 \%$ pomegranate-21\% orange), $25 \quad(60 \%$ olive- $28 \%$ pomegranate- $12 \%$ orange) and 56 (70\% olive-18\% pomegranate- $12 \%$ orange) which according to Tukey's test, differed statistically significantly from control sample number 69. It was generally observed that the higher the amount of olive fruit polyphenol contained in the sample mix, the more effective the inhibitory effect of the mixtures on the fungus $R$. solani was. In addition, no mycelium growth of $R$. solani was observed in the treatment with $100 \%$ olive fruit polyphenol (sample 70 ).

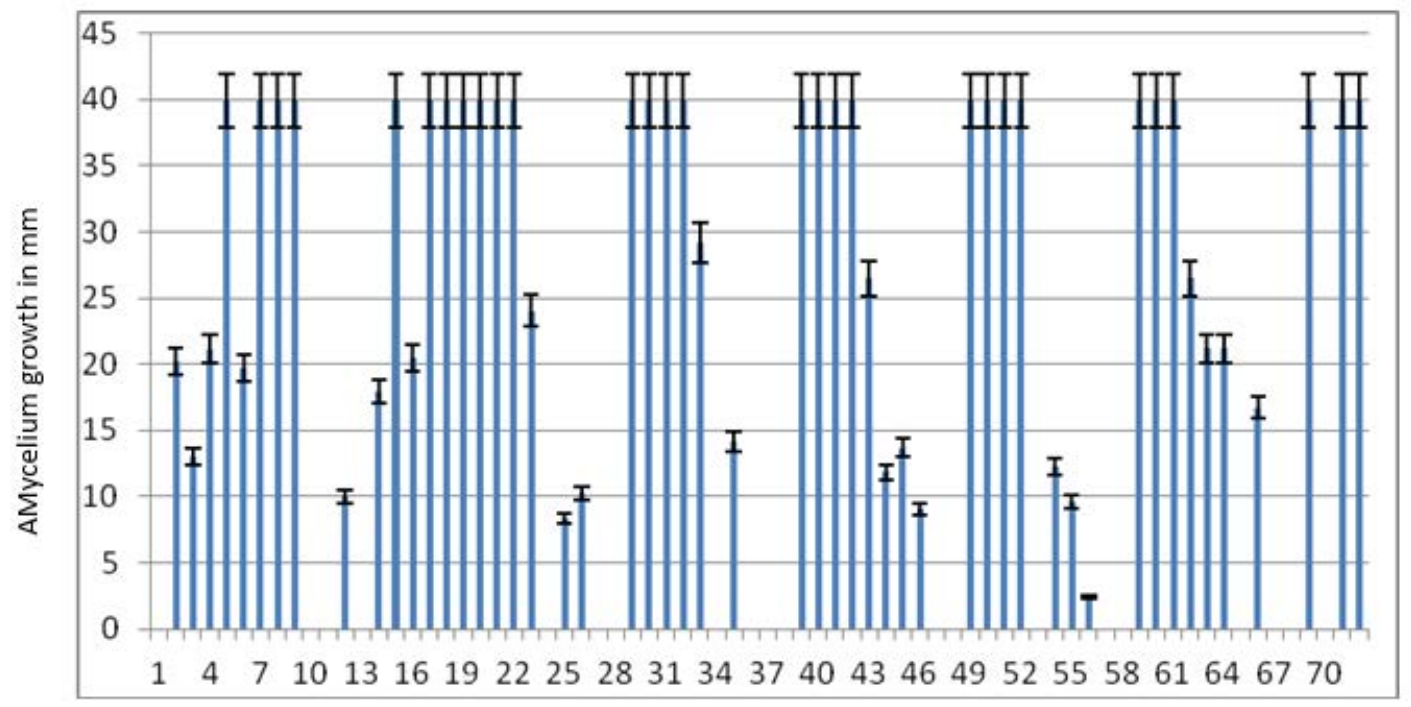

Sample number

Figure 5. Mycelium growth of $R$. solani 17 days after incubation at $28^{\circ} \mathrm{C}$. 
210 Potential Synergistic Action of Liquid Olive Fruit Polyphenol Extract with Aqueous Extracts of Solid Wastes of Pomegranate or/and Orange Juice Industry as Organic Phyto-protective Agents against Important Plant Pathogens - Part 1 (in vitro Studies)

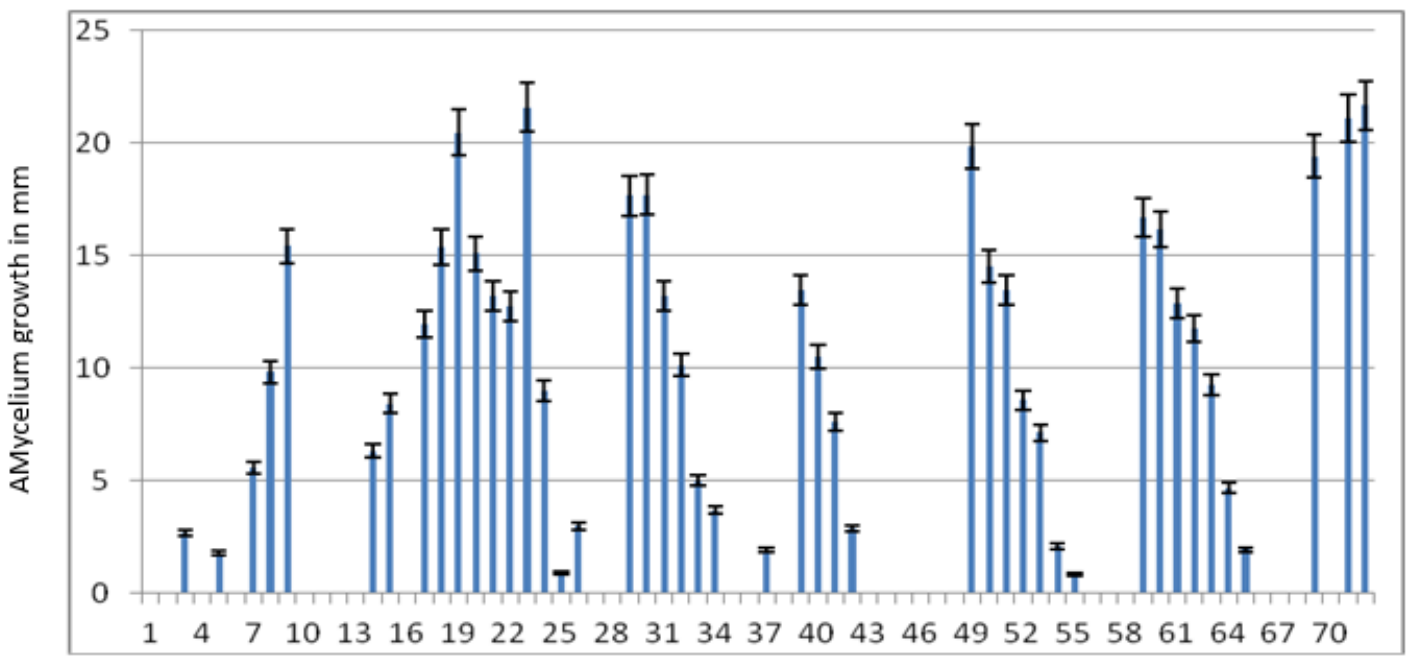

Sample number

Figure 6. Mycelium growth of E. lata 11 days after incubation at $28^{\circ} \mathrm{C}$.

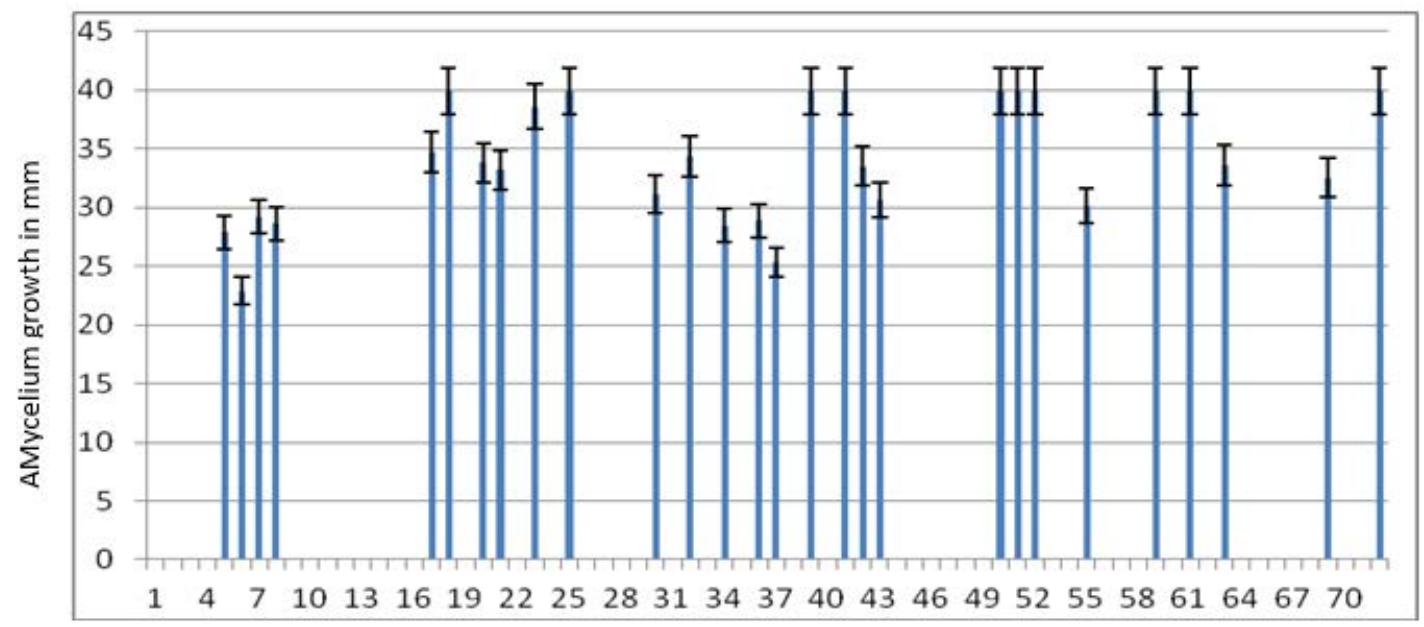

Sample number

Figure 7. Mycelium growth of $M$. laxa 14 days after incubation at $28^{\circ} \mathrm{C}$.

\subsubsection{Potential synergistic action on E. lata}

According to Figure 6 the mycelium of sample 69 (control) was covered Petri dish after 11 days of incubation at $28^{\circ} \mathrm{C}$. However, the highest growth of mycelium (even greater than the control 69) was observed in samples 72 (100\% orange), 23 (40\% olive-42\% pomegranate-18\% orange), $\quad 71 \quad(100 \%$ pomegranate $), \quad 19 \quad(70 \%$ pomegranate- $30 \%$ orange) and 49 (60\% pomegranate- $40 \%$ orange). According to Tukey's test, the above samples (72, $23,71,19,49)$ as well as samples $30(10 \%$ olive- $45 \%$ pomegranate- $45 \%$ orange), 29 (50\% pomegranate-50\% orange), and 59 (40\% pomegranate- $60 \%$ orange) did not differ statistically significantly from control sample 69 . No mycelium growth was observed in those samples in which olive fruit polyphenol was applied alone or in various olive-pomegranate and olive-orange mixtures at concentration of $60-70 \%$ and above. On the contrary, mycelium growth was observed in 12 new treatments (samples), where in the previous measurement (at 8 days) there was no mycelium appearance. Such samples are samples number 3, 5, 25, 26, 33, 34, 37, 54, 55, 63, 64 and
65 showing that any inhibitory activity of the polyphenols mixtures is affected by the exposure period to the microorganisms. The longer the time elapsed from the day the microorganisms are inoculated into the polyphenols solution, the lower their activity. No mycelium growth was observed in samples 1, 2, 5, 6, 10-13, 16, 27, 28, 35, 36, 38, 43-48, 56-58 and 66-68. However, limited mycelium growth was observed in samples: $9,18,20,50,51,39,21$, $31,61,22,17,62,40,32,8,63,24,52,15,41,53,14,7,33$, $64,34,26,42,3,54,65,37,5,25$ and 55 which, according to Tukey's test, differed statistically significantly from the mycelium growth observed in control 69. It was generally observed that the higher the amount of olive fruit polyphenol present in the mixing of the samples, the more effective the inhibitory effect of the mixtures on E. lata. In addition, no mycelium growth was observed in the treatment with $100 \%$ olive fruit polyphenol (sample 70 ).

\subsubsection{Potential synergistic action on M. laxa}

According to Figure 7 control sample (number 69) containing mycelium and spores of the M. laxa was 
covered the Petri dish area after 14 days of incubation at $28^{\circ} \mathrm{C}$. However, the greatest mycelium growth (even greater than the control 69) was observed in samples 72 (100\% orange), 61 (20\% olive-63\% pomegranate- $48 \%$ orange), 59 (40\% pomegranate-60\% orange), 52 (30\% olive- $42 \%$ pomegranate- $28 \%$ orange), 51 (20\% olive- $48 \%$ pomegranate-32\% $\quad$ orange), $\quad 41 \quad(20 \%$ olive- $24 \%$ pomegranate-56\% orange), $\quad 50 \quad(10 \% \quad$ olive-54\% pomegranate-36\% orange), 39 (30\% pomegranate- $90 \%$ orange), 25 ( $60 \%$ olive- $28 \%$ pomegranate- $12 \%$ orange), 18 (10\% olive-90\% orange), $23 \quad(40 \% \quad$ olive- $42 \%$ pomegranate-18\% orange) ), 17 (20\% olive- $80 \%$ orange), 32 (30\% olive-35\% pomegranate-35\% orange), 20 (10\% olive-63\% pomegranate-27\% orange), 63 ( $40 \%$ olive- $24 \%$ pomegranate-36\% orange), $42 \quad(30 \%$ olive- $21 \%$ pomegranate- $49 \%$ orange) and 21 (20\% olive-56\% pomegranate-24\% orange). According to Tukey's test, samples 23, 17, 32, 20, 63, 42, 21, 30, 43, 55, 7, 36, 8, 34 and 5 did not differ statistically important from the control sample 69. However, samples: 72, 61, 59, 52, 51, 50, 41, 39, 25 and 18 showed greater mycelial growth than the control (sample 69) and were statistically significantly different from the control. No mycelium growth was observed in those samples in which olive fruit polyphenol was applied at a concentration of $60 \%$ and above as well as in olive-orange mixture at an olive polyphenol concentration above $30 \%$. Also, no mycelium growth of M. laxa was observed in treatments where $90 \%$ pomegranate- $10 \%$ olive, $50 \%$ pomegranate- $50 \%$ orange was mixed and in some other individual cases. In addition, no mycelium growth was observed in additional treatments (samples) compared to the previous measurement at $11^{\text {th }}$ day of incubation suggesting that the possible inhibitory action of the polyphenol mixtures used in this study is not affected by the exposure period to the microorganisms. No mycelium growth was observed in samples: 1-4, 9-16, 19, 22, 24, $26-29,31,33,35,38,40,44-49,53,54,56-58,60.62$, 64-68, 70 and 71. According to Tukey's test, mycelium growth of samples 37, 6 and 68 differ statistically from sample 69 (control). It was generally observed that the higher the percentage of olive fruit polyphenol contained in the sample mix, the more effective the inhibitory activity of the samples was. In addition, treatment with $100 \%$ olive polyphenol (sample 70) and sample containing 100\% pomegranate (sample 71) did not allowed mycelium growth of M. laxa.

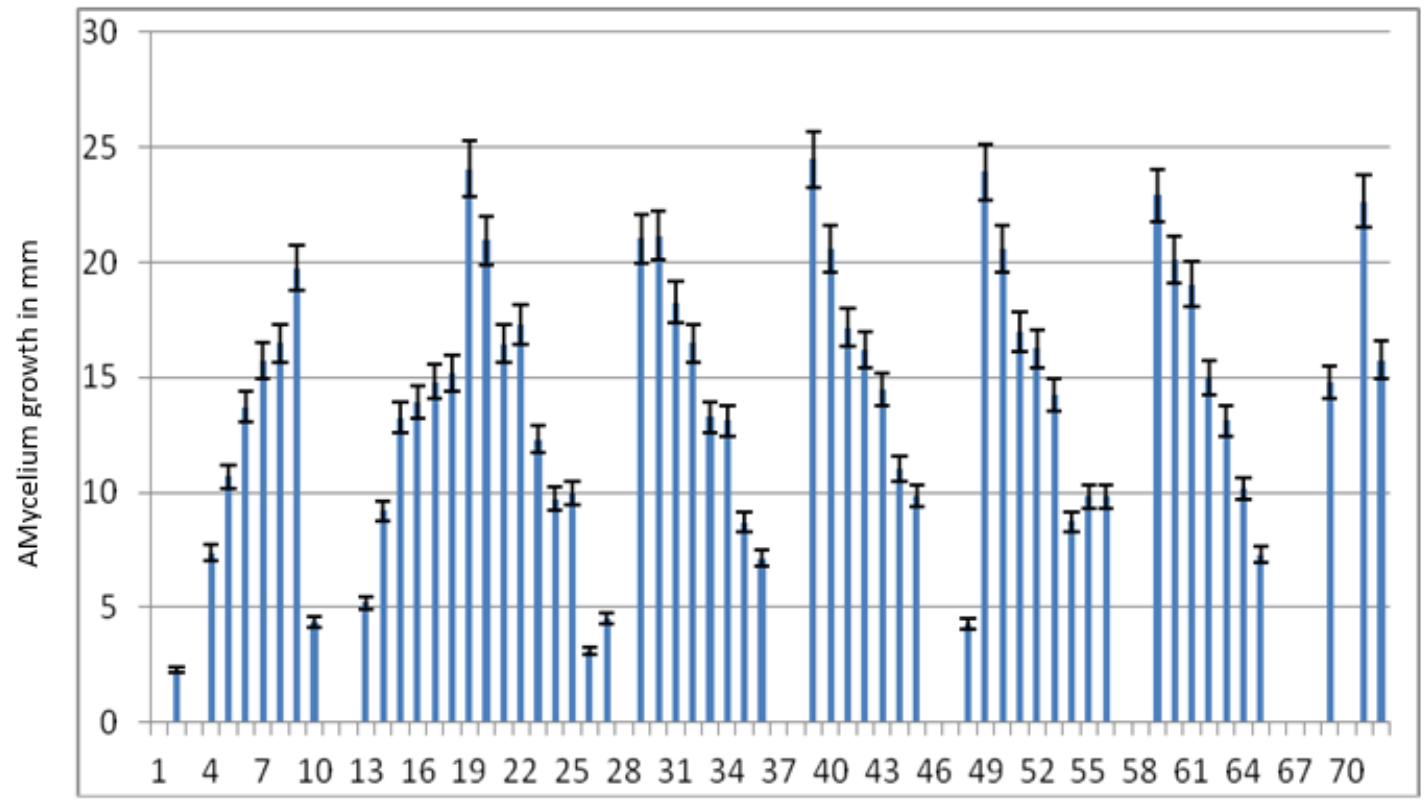

Sample number

Figure 8. Mycelium growth of $P$. lycopersici 14 days after incubation at $28{ }^{\circ} \mathrm{C}$. 
212 Potential Synergistic Action of Liquid Olive Fruit Polyphenol Extract with Aqueous Extracts of Solid Wastes of Pomegranate or/and Orange Juice Industry as Organic Phyto-protective Agents against Important Plant Pathogens - Part 1 (in vitro Studies)

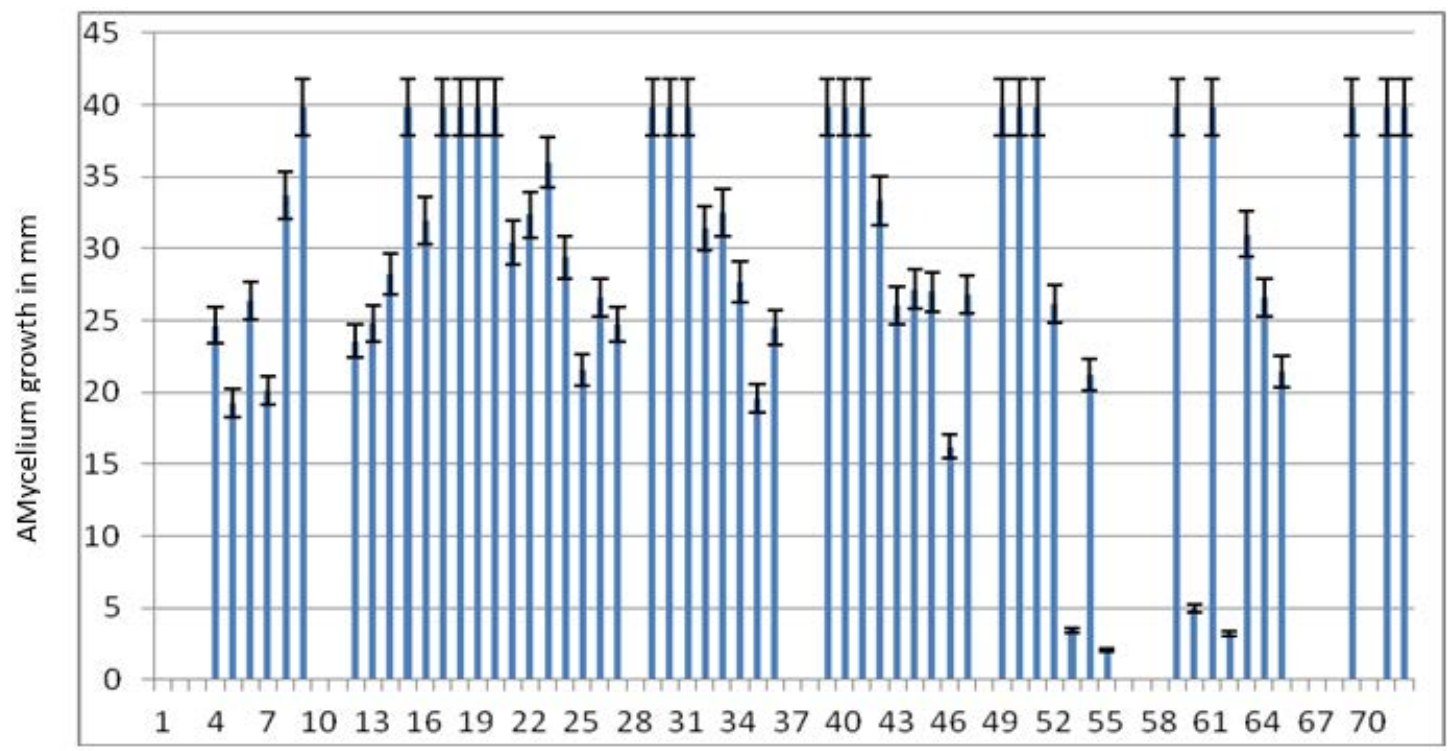

Sample number

Figure 9. Mycelium growth of $P$. punicae 14 days after incubation at $28^{\circ} \mathrm{C}$.

\subsubsection{Potential synergistic action on P. lycopersici}

According to Figure 8 control sample 69 containing only mycelium and spores of the fungus $P$. lycopersici was covered the Petri dish area after 14 days of incubation at $28^{\circ} \mathrm{C}$. However, the highest mycelium growth (even greater than the control 69) was observed in samples 39 (30\% pomegranate- $70 \%$ orange), 19 (70\% pomegranate- $30 \%$ orange), 49 (60\% pomegranate- $40 \%$ orange), 59 (40\% pomegranate- $60 \%$ orange), 71 (100\% pomegranate), 30 (10\% olive- $45 \%$ pomegranate- $45 \%$ orange), 29 (50\% pomegranate-50\% $\quad$ orange), $20 \quad(10 \% \quad$ olive-63\% pomegranate-27\% $\quad$ orange), $\quad 40 \quad(10 \% \quad$ olive-27\% pomegranate-63\% $\quad$ orange), $\quad 50 \quad(10 \% \quad$ olive- $54 \%$ pomegranate-36\% orange), $60 \quad$ ( $10 \%$ olive-36\% pomegranate-54\% orange), $9 \quad(10 \%$ olive- $90 \%$ pomegranate), 61 (20\% olive-32\% pomegranate- $48 \%$ orange), 31 ( $20 \%$ olive- $40 \%$ pomegranate- $40 \%$ orange), 41 ( $20 \%$ olive- $24 \%$ pomegranate-56\% orange), 22 (30\% olive- $49 \%$ pomegranate- $21 \%$ orange), 51 (20\% olive- $48 \%$ pomegranate-32\% orange), $8 \quad(20 \%$ olive- $80 \%$ pomegranate), 32 (30\% olive-35\% pomegranate-35\% orange), 21 (20\% olive-56\% pomegranate- $24 \%$ orange), 52 (30\% olive- $42 \%$ pomegranate-28\% orange), 42 (30\% olive-21\% pomegranate- $49 \%$ orange), 72 (100\% orange) , 7 (30\% olive-70\% pomegranate), 18 (10\% olive-90\% orange), 62 (30\% olive-28\% pomegranate- $42 \%$ orange) and 17 (20\% olive- $80 \%$ orange). According to Tukey's test, samples 22, 51, 8, 32, 21, 52, 42, 72, 7, 18, 62, 17, 43, 53, $16,6,33,15,34,63$ and 23 did not differ significantly importantfrom the control sample 69. No mycelium growth was observed in those samples in which olive fruit extract was applied alone or in pomegranate-orange mixtures at a concentration of $>80-90 \%$. In contrast, mycelium growth was observed in 6 new treatments (samples), where in the previous measurement (at 9 days) mycelium was not developed at all. Such treatments are samples: 2, 10, 13, 26, 27 and 48, suggested that any inhibitory activity of the polyphenolic mixtures is affected by the exposure period to the microorganisms. The longer the time elapsed from the day the microorganisms are inoculated into the polyphenols solution, the lower their activity. No mycelium growth was observed in samples 1 (90\% olive- $10 \%$ pomegranate), 3 ( $70 \%$ olive-30\% pomegranate), 11 ( $80 \%$ olive- $20 \%$ orange), 12 (70\% olive-30\% orange), 37 (80\% olive- $10 \%$ pomegranate- $10 \%$ orange), 38 (90\% olive-5\% pomegranate-5\% orange), 46 (70\% olive- $9 \%$ pomegranate- $21 \%$ orange), $47 \quad(80 \%$ olive $-6 \%$ pomegranate-14\% $\quad$ orange), $56 \quad(70 \%$ olive- $18 \%$ pomegranate-12\% $\quad$ orange), $57 \quad(80 \% \quad$ olive- $12 \%$ pomegranate- $8 \%$ orange), 58 (90\% pomegranate-6\% pomegranate- $\quad 4 \%$ orange), $66 \quad(70 \%$ olive- $12 \%$ pomegranate- $18 \%$ orange $), \quad 67 \quad(80 \% \quad$ olive- $8 \%$ pomegranate- $12 \%$ orange), $68 \quad(80 \% \quad$ olive- $8 \%$ pomegranate- $12 \%$ orange) and 70 (100\% olive). Smaller mycelium growth that was statistically significantly different compared to the control (69) was observed in samples: 44, 5, 64, 25, 45, 56, 55, 24, 14, 54, 35, 4, 65 , 36, $13,27,10,48,26$ and 2. It was generally observed that the higher the amount of olive fruit polyphenol extract contained in the sample mix, the more effective the inhibitory activity of the mixtures on P. lycopersici was. In addition, no mycelium growth of $P$. lycopersici was observed in the treatment containing $100 \%$ olive fruit polyphenol (sample 70).

\subsubsection{Potential synergistic action on P. punicae}

According to Figure 9 control sample (69) of $P$. punicae was covered the growth are of the Petri dish after 14 days 
of incubation at $28{ }^{\circ} \mathrm{C}$. Similar mycelium growths, were also observed in samples 72 (100\% orange), 71 (100\% pomegranate), 61 (20\% olive-32\% pomegranate-48\% orange), 59 (40\% pomegranate- $60 \%$ orange), 51 (20\% olive-48\% pomegranate-32\% orange), 50 (10\% olive-54\% pomegranate- $36 \%$ orange), 49 (60\% pomegranate- $40 \%$ orange), 31 (20\% olive- $40 \%$ pomegranate- $40 \%$ orange), 30 (10\% olive- $45 \%$ pomegranate- $45 \%$ orange), 29 (50\% pomegranate-50\% orange), $20 \quad(10 \%$ olive-63\% pomegranate-27\% orange), 19 (70\% pomegranate-30\% orange), 18 ( $10 \%$ olive-90\% orange), 17 (20\% olive- $80 \%$ orange), 15 (40\% olive-60\% orange) and 9 (10\% olive$90 \%$ pomegranate). According to Tukey's test, samples 72 , 71, 69, 61, 59, 51, 50, 49, 31, 30, 29, 20, 19, 18, 17, 15, 9 did not differ statistically important from the control sample number 69. Mycelium growth was not observed in those samples in which olive fruit extracted polyphenol was applied alone at $>70 \%$ as well as in mixtures with pomegranate at $>90 \%$. On the contrary, mycelium growth was observed in 5 new treatments, where in the previous measurement (9 days) no mycelium growth was observed. These samples was samples 46, 53, 55, 60 and 62 demonstrating that any inhibitory activity of the polyphenolic mixtures is affected by the exposure period to the microorganisms. The longer the time elapsed from the day the microorganisms are inoculated into the polyphenolic solution, the lower their activity. No mycelium growth was observed in samples 1 (90\% olive- $10 \%$ pomegranate), 2 (80\% olive- $20 \%$ pomegranate), 3 (70\% olive-30\% pomegranate), 10 (90\% olive- $10 \%$ orange), 11 ( $80 \%$ olive- $20 \%$ orange), 28 (90\% olive-7\% pomegranate-3\% orange), $37 \quad(80 \% \quad$ olive- $10 \%$ pomegranate- $10 \%$ orange), $38 \quad(90 \%$ olive-5\% pomegranate) $\quad-5 \% \quad$ orange), $46 \quad(70 \% \quad$ olive- $9 \%$ pomegranate-21\% $\quad$ orange), $48 \quad(90 \%$ olive-3\% pomegranate- $7 \%$ orange), $56 \quad(70 \%$ olive- $18 \%$ pomegranate- $12 \%$ orange), $\quad 57 \quad(80 \% \quad$ olive- $12 \%$ pomegranate-8\% orange), 58 (90\% pomegranate-6\% pomegranate- $4 \%$ orange), $66 \quad(70 \%$ olive- $12 \%$ pomegranate- $18 \% \quad$ orange $), \quad 67 \quad(80 \% \quad$ olive- $8 \%$ pomegranate- $12 \%$ orange), $68 \quad(80 \%$ olive-8\% pomegranate- $12 \%$ orange) and 70 (100\% olive). Mycelium growth that was statistically significantly different according to the Tukey's test compared to the control (69) was observed in the samples: $8,42,33,22,16,32,63,21$, $24,14,34,44,45,47,26,64,6,52,43,1 ` 3,27,4,36,12$, $25,65,54,7,35,5,37,8,46,60,53,62$ and 55 It has generally been observed that the higher the amount of olive polyphenol present in the mixing of the samples, the more effective the inhibitory effect of the mixtures on the $P$. punicae fungus was. In addition, no mycelium growth of $P$. punicae was observed in the treatment containing $100 \%$ olive fruit extract polyphenol (sample 70).

\subsection{Results on MIC/MLC Assay}

The results of the effect of different concentrations and mixtures of the extracts tested by the method of MIC /
MLC described in Table 3. The evaluation of the results obtained by determining the MIC and MLC (Tables 3) demonstrated that $R$. solani showed high growth sensitivity at the very low concentration of the tested extracts $(<2,5 \%)$. Based on these results, it is understood that the use of the tested extracts might be an alternative, bio-control method of plant diseases caused by this soil borne pathogen. However, disease control of $R$. solani is considered difficult since the phytopathogenic fungus mainly affects the roots and the stem of young plants and spray application application straight to the target-plant tissue is not sufficient. Moreover, the morphological characteristics of the fungal specie such as sclerotia which are resistant to adverse environmental conditions and applications of plant protective materials resulting control of the fungus less effective. Furthermore, results obtained by determination of the MIC and MLC demonstrated that the fungi $P$. lycopersici and E. lata were sensitive in expression of low concentration of the tested extracts 2,5\%-5\% and 5\%-7,5\% respectively while mycelium growth of $V$. dahliae and $P$. punicae was affected in expression of a higher of the tested extracts (> 7.5\%). Thus, the examined extracts could be used as an alternative biocontrol agent against the two plant pathogens even in a low concentration, directly on plant tissues and infected stems of the crops preventing and suppressing the development of the two pathogens. Finally, MIC and MLC results on fungi B. cinerea, M. laxa, and $F$. oxysporum f.sp., lycopersici shown moderate sensitivity to the tested extracts while at least $10 \%$ of the concentration was needed to be applied in order to inhibit mycelium growth and spore germination. Therefore, in order to classify the effectiveness of the tested extracts (samples) against the tested fungal pathogens it was created the following list (Table 4) with the most sensitive and the most resistant fungal species.

Overall, for the control of $B$. cinerea it is recommended the use of:

- Olive fruit polyphenol extract at $100 \%$.

- Pomegranate polyphenol extract at $100 \%$.

- Olive-pomegranate polyphenol extract at combinations from $90-10 \%$ to $60-40 \%$ (olive-pomegranate).

- Olive-orange polyphenol extract combinations from $90-10 \%$ to $50-50 \%$ (olive-orange).

- Various olive-pomegranate-orange polyphenol extract combinations as it shown in the results section.

for the control of $V$. dahliae it is recommended the use of:

- Olive fruit polyphenol extract at $100 \%$.

- Olive-pomegranate polyphenol extract at combinations from $90-10 \%$ to $20-80 \%$ (olive-pomegranate).

- Olive-orange polyphenol extract combinations from $90-10 \%$ to $30-70 \%$ (olive-orange).

- Various olive-pomegranate-orange polyphenol extract combinations where at least $20 \%$ olive fruit polyphenol extract is contained added in the mixture. 
214 Potential Synergistic Action of Liquid Olive Fruit Polyphenol Extract with Aqueous Extracts of Solid Wastes of Pomegranate or/and Orange Juice Industry as Organic Phyto-protective Agents against Important Plant Pathogens - Part 1 (in vitro Studies)

for the control of $R$. solani it is recommended the use of:

- $\quad$ Olive fruit polyphenol extract at $100 \%$.

- Olive-pomegranate polyphenol extract at combinations from $90-10 \%$ (olive-pomegranate).

- $\quad$ Olive-orange polyphenol extract combinations from $90-10 \%$ to $80-20 \%$ (olive-orange).

- Various olive-pomegranate-orange polyphenol extract combinations as it shown in the results section.

for the control of E. lata it is recommended the use of:

- $\quad$ Olive fruit polyphenol extract at $100 \%$.

- Olive-pomegranate polyphenol extract at combinations from $90-10 \%$ to $40-60 \%$ (olive-pomegranate).

- Olive-orange polyphenol extract combinations from $90-10 \%$ to $40-60 \%$ (olive-orange).

- Various olive-pomegranate-orange polyphenol extract combinations as it shown in the results section.

for the control of M. laxa it is recommended the use of:

- $\quad$ Olive fruit polyphenol extract at $100 \%$.

- $\quad$ Pomegranate peels polyphenol extract at $100 \%$.

- $\quad$ Olive-pomegranate polyphenol extract at combinations from $90-10 \%$ to $60-40 \%$ (olive-pomegranate).
- Olive-orange polyphenol extract combinations from $90-10 \%$ to $60-40 \%$ (olive-orange).

- Various olive-pomegranate-orange polyphenol extract combinations as it shown in the results section.

for the control of $P$. lycopersici it is recommended the use of:

- Olive fruit polyphenol extract at $100 \%$.

- Olive-pomegranate polyphenol extract at combinations from $90-10 \%$ to $70-30 \%$ (olive-pomegranate).

- Olive-orange polyphenol extract combinations from 90-10\% to $70-30 \%$ (olive-orange).

- Various olive-pomegranate-orange polyphenol extract combinations as it shown in the results section.

for the control of $P$. punicae it is recommended the use of:

- $\quad$ Olive fruit polyphenol extract at $100 \%$.

- Olive-pomegranate polyphenol extract at combinations from $90-10 \%$ to $70-30 \%$ (olive-pomegranate).

- Olive-orange polyphenol extract combinations from $90-10 \%$ to $80-20 \%$ (olive-orange).

- Various olive-pomegranate-orange polyphenol extract combinations as it shown in the results section. 
Table 3. MIC and MLC test of olive fruit, pomegranate and orange peels extracts on 10 plant pathogens

\begin{tabular}{|c|c|c|c|c|c|c|c|c|c|c|c|}
\hline & & B. cinerea & V. dahliae & E. lata & M. laxa & R. solani & P. lycopersici & P.punicae & F. oxysporum & A. niger & G. graminis \\
\hline \multirow{5}{*}{ Sample 1} & $0 \%$ & + & + & + & + & + & + & + & + & + & + \\
\hline & $2,5 \%$ & + & + & + & + & - & + & + & + & + & + \\
\hline & $5 \%$ & + & + & + & + & - & - & + & + & + & + \\
\hline & $7,5 \%$ & + & - & - & + & - & - & - & + & + & + \\
\hline & $10 \%$ & + & - & - & + & - & - & - & + & + & + \\
\hline \multirow{5}{*}{$\begin{array}{c}\text { Sample } \\
10\end{array}$} & $0 \%$ & + & + & + & + & + & + & + & + & + & + \\
\hline & $2,5 \%$ & + & + & + & + & - & + & + & + & + & + \\
\hline & $5 \%$ & + & + & + & + & - & - & + & + & + & + \\
\hline & $7,5 \%$ & + & - & - & + & - & - & - & + & + & + \\
\hline & $10 \%$ & + & - & - & + & - & - & - & + & + & + \\
\hline \multirow{5}{*}{$\begin{array}{c}\text { Sample } \\
11\end{array}$} & $0 \%$ & + & + & + & + & + & + & + & + & + & + \\
\hline & $2,5 \%$ & + & + & + & + & - & + & + & + & + & + \\
\hline & $5 \%$ & + & + & + & + & - & - & + & + & + & + \\
\hline & $7,5 \%$ & + & + & - & + & - & - & - & + & + & + \\
\hline & $10 \%$ & + & + & - & + & - & - & - & + & + & + \\
\hline \multirow{5}{*}{$\begin{array}{c}\text { Sample } \\
28\end{array}$} & $0 \%$ & + & + & + & + & + & + & + & + & + & + \\
\hline & $2,5 \%$ & + & + & + & + & - & + & + & + & + & + \\
\hline & $5 \%$ & + & + & + & + & - & - & + & + & + & + \\
\hline & $7,5 \%$ & + & - & - & + & - & - & - & + & + & + \\
\hline & $10 \%$ & + & - & - & + & - & - & - & + & + & + \\
\hline \multirow{5}{*}{$\begin{array}{c}\text { Sample } \\
46\end{array}$} & $0 \%$ & + & + & + & + & + & + & + & + & + & + \\
\hline & $2,5 \%$ & + & + & + & + & - & + & + & + & + & + \\
\hline & $5 \%$ & + & + & + & + & - & - & + & + & + & + \\
\hline & $7,5 \%$ & + & + & - & + & - & - & + & + & + & + \\
\hline & $10 \%$ & + & + & - & + & - & - & + & + & + & + \\
\hline
\end{tabular}


Table 3 Continuous

\begin{tabular}{|c|c|c|c|c|c|c|c|c|c|c|c|}
\hline \multirow{5}{*}{$\begin{array}{c}\text { Sample } \\
48\end{array}$} & $0 \%$ & + & + & + & + & + & + & + & + & + & + \\
\hline & $2,5 \%$ & + & + & + & + & - & + & + & + & + & + \\
\hline & $5 \%$ & + & + & + & + & - & - & + & + & + & + \\
\hline & $7,5 \%$ & + & - & - & + & - & - & - & + & + & + \\
\hline & $10 \%$ & + & - & - & + & - & - & - & + & + & + \\
\hline \multirow{5}{*}{$\begin{array}{c}\text { Sample } \\
57\end{array}$} & $0 \%$ & + & + & + & + & + & + & + & + & + & + \\
\hline & $2,5 \%$ & + & + & + & + & - & + & + & + & + & + \\
\hline & $5 \%$ & + & + & + & + & - & - & + & + & + & + \\
\hline & $7,5 \%$ & + & + & - & + & - & - & - & + & + & + \\
\hline & $10 \%$ & + & + & - & + & - & - & - & + & + & + \\
\hline \multirow{5}{*}{$\begin{array}{c}\text { Sample } \\
58\end{array}$} & $0 \%$ & + & + & + & + & + & + & + & + & + & + \\
\hline & $2,5 \%$ & + & + & + & + & - & + & + & + & + & + \\
\hline & $5 \%$ & + & + & + & + & - & - & + & + & + & + \\
\hline & $7,5 \%$ & + & - & - & + & - & - & - & + & + & + \\
\hline & $10 \%$ & + & - & - & + & - & - & - & + & + & + \\
\hline \multirow{5}{*}{$\begin{array}{c}\text { Sample } \\
67\end{array}$} & $0 \%$ & + & + & + & + & + & + & + & + & + & + \\
\hline & $2,5 \%$ & + & + & + & + & - & + & + & + & + & + \\
\hline & $5 \%$ & + & + & + & + & - & - & + & + & + & + \\
\hline & $7,5 \%$ & + & - & - & + & - & - & - & + & + & + \\
\hline & $10 \%$ & + & - & - & + & - & - & - & + & + & + \\
\hline \multirow{5}{*}{$\begin{array}{c}\text { Sample } \\
70\end{array}$} & $0 \%$ & + & + & + & + & + & + & + & + & + & + \\
\hline & $2,5 \%$ & + & + & + & + & - & + & + & + & + & + \\
\hline & $5 \%$ & + & + & + & + & - & - & + & + & + & + \\
\hline & $7,5 \%$ & + & - & - & + & - & - & - & + & + & + \\
\hline & $10 \%$ & + & - & - & + & - & - & - & + & + & + \\
\hline
\end{tabular}

+ Mycelium growth

- No mycelium growth (mycelium suspension) 
Table 4. Fungi sensitivity on different concentrations of the tested extracts

\begin{tabular}{ccc}
\hline $\begin{array}{c}\text { Most } \\
\text { Sensitive }\end{array}$ & Rhizoctonia solani & $<\mathbf{2 , 5 \%}$ \\
\hline & Pyrenochaeta lycopersici & $2,5 \%-5 \%$ \\
\hline Eutypa lata & $5 \%-7,5 \%$ \\
\hline Verticillium dahliae & \\
Phoma punicae & \\
Botrytis cinerea & \\
Monillia laxa & $>7,5 \%$ \\
& Fusarium oxysporum f.sp. & \\
lycopersici & \\
Most Resistant & Gaeumanomyces graminis & \\
\hline
\end{tabular}

\section{Discussion}

Waste biomass produced by agricultural sector and the food supply chain poses an unprecedented risk to public health by polluting land and water resources. The main objective of the European Union's (EUs) environmental policy is the development of various sectors such as agriculture, industry and energy production with zero emission of pollutants without causing any environmental burden. However, achieving this goal in many cases is particularly difficult. In Greece, as in many other European countries agricultural development is still not considered to be fully in line with these objectives. Large volumes of residual by-products of existing activities such as olive oil production are considered to constitute additional economic revenue after appropriate treatment thus limiting environmental risks while at the same time covering environmental protection rules. Also, these residues waste or by-products is believed to be able to both reduce the environmental problem from their activity and create new jobs at the same time. It is also believed that the utilization and management of residues and by-products from this process could also help to issue an eco-label for those products derived from production processes with little or no environmental impact [58]. In this way consumers could easily discern which products are more or less harmful to the environment.

Thus, the interest in the isolation, examination and use of plant tissues and agricultural waste rich in natural polyphenols extracted from various parts of plant species such as thyme, citrus and olive green tea has been expressed by many researchers [59-73]. This interest is strongly enhanced since several microorganisms such as fungi, bacteria, viruses, etc., interact in the natural environment with plants [74-76] and by them shelves [77] affecting growth and development $[78,78,79]$.

Studies carried out on parts of pomegranate plant $[18,19]$ showed that peels, flowers and pomegranate juice contained different types of antioxidants such as anthocyanins, catechins and ellagitans. These compounds could obviously play an important role in improving human health when added to food products through their effect on slowing down the lipid peroxidation process by presenting anti-cancer, antimicrobial, antioxidant, antiviral ${ }^{80-83}$ and plant protection action [84]. More specific, in vitro studies demonstrated the bactericidal activity against many antibiotic resistant pathogens [85-90].

Furthermore, studies on the use of OMWW has been demonstrated that it can act as phytoprotective compound on fruits and vegetables during the growing season and after harvest during storage offering a promising solution for preventing losses of fruits and vegetables from post-harvest attacks such as those from the fungus $B$. cinerea $[69,73]$. Similar results have been reported by other studies [65,91-93] where the use of OMWW can affect the growth of saprophytic fungi, the incidence of foliar diseases, and the growth of soil-borne pathogens before and after harvest in strawberries and in tulip plants. Furthermore, in another study has been reported that substances extracted from OMWW showing antifungal action inhibited the mycelium growth of Fusarium solani and $R$. solani [94]. Similar results were reported also in a study against $R$. solani in field experiments [64]. Various forms of OMWW polyphenols and especially the liquid one have been also reported that affect the development of several important plant pathogenic fungi such as $B$. cinerea, A. alternata, F. oxysporum f.sp., melonis, Rhizopus species, C. higginsianum, and P. parasitica var. nicotianae [95].

\section{Conclusions}

In conclusion, the findings of this study demonstrate a species-specific in vitro inhibition and potential synergistic activity of aqueous extracts of olive-pomegranate-orange fruits isolated by microwave assisted extraction. The olive fruit extract showed a clear inhibition of $B$. cinerea, $V$. dahliae, $R$. solani, E. lata, M. laxa, P. lucopersici and $P$. punicae in terms of affected the mycelium growth while did not affect the mycelium growth of $F$. oxysporum $\mathrm{f}$. sp., lycopersici, A. niger, and G. graminis. Furthermore, the use of any combination and concentrations of the tested samples (1-72) did not affect the mycelium growth of $F$. oxysporum f. sp., lycopersici, A. niger, and G. graminis thus, their use as biological control agent is not recommended.

From the above it is clear that the olive fruit polyphenol extract has presented encouraging results, but the effectiveness should be studied further. The encapsulation of a polyphenol in encapsulating agent may help to slow the degradation and protection from the frequent watering and runoff due to this action.

\section{Acknowledgements}

This research has been co-financed by the European 
218 Potential Synergistic Action of Liquid Olive Fruit Polyphenol Extract with Aqueous Extracts of Solid Wastes of Pomegranate or/and Orange Juice Industry as Organic Phyto-protective Agents against Important Plant Pathogens - Part 1 (in vitro Studies)

Regional Development Fund of the European Union and Greek National funds through the Operational Program Competitiveness, Entrepreneurship and Innovation, under the call RESEARCH - CREATE - INNOVATE (Project code: T1EDK-03942). Also, Benaki Phytopathological Institute is ackno

\section{Author Contributions}

S.L., conducted the experiments, the data analysis and wrote the manuscript. C.M., conducted the experiments. I.G., supervised the experiments, and reviewed the manuscript. K.P., C.P. and I.V. were involved in the production of samples and checked the manuscript. All authors have read and agreed to the published version of the manuscript.

\section{Conflicts of Interest}

The authors declare no conflict of interest.

\section{REFERENCES}

[1] Leistner I., "Basic aspects of food preservation by hurdle technology," International Journal of Food Microbiology, vol 55, pp. 181-186, 2000. DOI: 10.1016/S0168-1605(00)0 0161-6

[2] International Olive Council, "International olive oil production costs study: Results, conclusions and recommendations,” 2015. DOI: 10.1016/S0168-1605(00)00 161-6

[3] Raina B.L., “Olives”, 2003, pp. 4260-4267.

[4] FAO Statistics, "Production of oranges, 2017-choose Production, Crops, World Regions in the left margin and picklist," 2018: United Nations.

[5] Celik I., Temur A., Isik, I., A. Hepato, "Protective role and antioxidant capacity of pomegranate (Punica granatum) flowers in fusion against trichloro-acetic acid- exposed in rats,” Food and Chemical Toxicology, vol. 47, pp. 145-149, 2009.

[6] Syed D.N., Afaq F., Kweon M.H., Hadi N., Bhatia N., Spiegelman V.S., H. Mukhtar, "Green tea polyphenol EGCG suppresses cigarette smoke condensate-induced NF-kappaB activation in normal human bronchial epithelial cells," Oncogene, vol. 26, pp. 673-682, 2007. DOI: 10.1038/sj.onc.1209829

[7] Aviram M., Dornfeld L., Rosenblat M., Volkova N., Kaplan M., Coleman R., Hayek T., Presser, D., B. Fuhrman, "Pomegranate juice consumption reduces oxidative stress, atherogenic modifications to LDL, and platelet aggregation: studies in humans and in atherosclerotic apolipoprotein E-deficient mice,” American Journal of Clinical Nutrition, vol. 71 no. 5, pp. 1062-1076, 2000. DOI:

\subsection{3/ajcn/71.5.1062}

[8] Gil M., Tomas-Barberan F., B, Hess-Pierce, “Antioxidant activity of pomegranate juice and its relationship with phenolic composition and processing," Journal of Agriculture and Food Chemistry, vol. 48, pp. 4581-4589, 2000. DOI: $10.1021 /$ jf000404a.

[9] Cerdá B., Espín J.C., Parra S., Martínez P., F.A. Tomás-Barberán, "The potent in vitro antioxidant ellagitannins from pomegranate juice are metabolised into bioavailable but poor antioxidant hydroxy-6H-dibenzopyra n-6-one derivatives by the colonic microflora of healthy humans," European Journal of Nutrition, vol. 43, no. 4, pp. 205-220, 2004. DOI: 10.1007/s00394-004-0461-7

[10] Cerdá B., Tomás-Barberán F.A., J.C. Espín, “Metabolism of antioxidant and chemopreventive ellagitannins from strawberries, raspberries, walnuts, and oak-aged wine in humans: identification of biomarkers and individual variability,” Journal of Agriculture and Food Chemistry, vol. 53, no. 2, pp. 227-235, 2005. DOI: 10.1021/jf049144d

[11] Seeram N.P., Lee R., D. Heber, "Bioavailability of ellagic acid in pomegranate (Punica granatum L.) juice,” Clinica Chimica Acta, vol. 348, no. 1-2, pp. 63-68, 2004. DOI: 10.1016/j.cccn.2004.04.029

[12] Seeram N.P., Adams L.S., Henning S.M., Niu Y., Zhang Y., Nair M.G., D. Heber, "In vitro antiproliferative, apoptotic and antioxidant activities of punicalagin, ellagic acid and a total pomegranate tannin extract are enhanced in combination with other polyphenols as found in pomegranate juice,” Journal of Nutrient Biochemistry, vol. 16, no. 6, pp. 360-367, 2005. DOI: 10.1016/j.jnutbio.2005.0 1.006

[13] Seeram N.P., Aviram M., Zhang Y., Henning S.M., Feng L., Dreher M., D. Heber, "Comparison of antioxidant potency of commonly consumed polyphenol-rich beverages in the United States,” Journal of Agriculture and Food Chemistry, vol. 56, no. 4, pp. 1415-1422, 2013. DOI: 10.1021/jf073035s

[14] Mertens-Talcott S.U., Jilma-Stohlawetz P., Rios J., Hingorani L., H. Derendorf, “Absorption, metabolism, and antioxidant effects of pomegranate (Punica granatum L.) polyphenols after Ingestion of a standardized extract in healthy human volunteers,” Journal of Agriculture and Food Chemistry, vol. 54, no. 23, pp. 8956-8961, 2006. DOI: 10.1021/jf061674h

[15] Lansky E.P., R.A. Newman, "Punica granatum (pomegranate) and its potential for prevention and treatment of inflammation and cancer," Journal of Ethnopharmacology, vol. 109, no. 2, pp. 177-206, 2007. DOI: 10.1016/j.jep.2006.09.006

[16] Petti S., C. Scully, "Polyphenols, oral health and disease: A Review,” Journal of Dentistry, vol. 37, no. 6, pp. 413-423, 2009. DOI: 10.1016/j.jdent.2009.02.003

[17] Basu A., K. Penugonda, "Pomegranate juice: A heart-healthy fruit juice," Nutrition Review, vol. 67, no. 1, pp. 49-56, 2009. DOI: 10.1111/j.1753-4887.2008.00133.x

[18] Duman A.D., Ozgen M., Dayisoylu K.S., Erbil N., C. Durgac, “Antimicrobial activity of six pomegranate (Punica granatum L.) varieties and their relation to some of their pomological and phytonutrient characteristics,” Molecules, vol. 14, pp. 1808-1817, 2009. DOI: 10.3390/molecules1405 
1808

[19] Hayrapetyan H., Hazeleger W.C., R.R. Beumer, “Inhibition of Listeria monocytogenes by pomegranate (Punica granatum) peel extract in meat paté at different temperatures,” Food Control, vol. 23, pp. 66-72, 2012. DOI: 10.1016/j.foodcont.2011.06.012

[20] John K.M.M, Bhagwat A.A., L.D. Luthria, "Swarm motility inhibitory and antioxidant activities of pomegranate peel processed under three drying conditions,” Food Chemistry, vol. 235, pp. 145-153, 2017. DOI: 10.1016/j.foodchem.201 7.04 .143

[21] Sahin F., Gulluce M., Daferera D., Sokmen A., Sokmen M., Polissiou M., Agar G., H. Ozer, "Biological activities of the essential oils and methanol extract of Origanum vulgare sp. vulgare in the Eastern Anatolia region of Turkey," Food Control, vol. 15, pp. 549-557, 2004. DOI: 10.1016/j.foodcont.2003.08.009

[22] Newman D.J., G.M. Cragg, "Natural products as sources of new drugs over the last 25 years," Journal of Natural Products, vol. 70, pp. 461-477, 2007. DOI: $10.1021 / \mathrm{np} 068054 \mathrm{v}$

[23] Kordali S., Cakir A.,Ozer H., Çakmakçı R., Kesdek M., E. Mete, "Antifungal, phytotoxic and insecticidal properties of essential oil isolated from Turkish Origanum acutidens and its three components, carvacrol, thymol and p-cymene," Bioresource Technology, vol. 99, no. 18, pp. 8788-8795, 2008. DOI: 10.1016/j.biortech.2008.04.048

[24] Schafer H., M. Wink, "Medicinally important secondary metabolites in recombinant microorganisms or plants: progress in alkaloid biosynthesis,” Biotechnology Journal, vol. 4, pp. 1684-1703, 2009. DOI: 10.1002/biot.200900229

[25] Katan J. "Diseases caused by soiborne pathogens: Biology, management and challenges," Journal of Plant Pathology, vol. 99, no. 2, pp. 305-315, 2017. DOI: 10.4454/jpp.v99i2.3862

[26] Abd El Nasser El Gendy, El Gohary A.E., Omer E., Hendawy S.F., Wahby M.S., Petrova V., I. Stancheva, "Effect of nitrogen and potassium fertilizer on herbage and oil yield of chervil plant (Anthriscus cerefolium L.)," Industrial Crops and Products, vol. 69, pp. 167-174, 2015. DOI: 10.1016/j.indcrop.2015.02.023

[27] Hajlaoui H., Hedi M., Aouni, M., Gharsallah, N., A. Kadri, "Chemical composition and in vitro evaluation of antioxidant, antimicrobial, cytotoxicity and anti-acetylcholi nesterase properties of Tunisian Origanum majorana L. essential oil,” Microbiology Pathology, vol. 95, pp. 86-94, 2016. DOI: 10.1016/j.micpath.2016.03.003

[28] Delgoda R., J.E. Murray, J.E. “Evolutionary perspectives on the role of plant secondary metabolites,” Pharmacognosy, pp. 93-100, 2017. DOI: 10.1016/B978-0-12-802104-0.00007-X

[29] Jamwal K., Bhattacharya S., S, Pur, “Plant growth regulator mediated consequences of secondary metabolites in medicinal plants," Journal of Applied Residue Mediterranean Aromatic Plants, vol. 9, pp. 26-38, 2018. DOI: 10.1016/j.jarmap.2017.12.003

[30] Neugart S., Baldermann S., Hanschen F.S., Klopsch R., Wiesner-Reinhold M., M. Schreiner, "The intrinsic quality of brassicaceous vegetables: How secondary plant metabolites are affected by genetic, environmental, and agronomic factors," Scientific Horticulture, vol. 233, pp. 460-478, 2018. DOI: 10.1016/j.scienta.2017.12.038

[31] Rao R.S., G.A. Ravishankar, "Plant tissue cultures; Chemical factories of secondary metabolites," Biotechnology Advances, vol. 20, no. 2, pp. 101-153, 2002. DOI: 10.1016/S0734-9750(02)00007-1

[32] Skenderidis P., Lampakis D., Giavasis I., Leontopoulos S., Petrotos K., Hadjichristodoulou C., A. Tsakalof, “Chemical properties, fatty-acid composition, and antioxidant activity of goji berry (Lycium barbarum L. and Lycium chinense Mill.) fruits,” Antioxidant, vol. 8, no. 60, pp. 1-13, 2019. DOI: 10.3390/antiox8030060

[33] Skenderidis P., Mitsagga Ch., Lampakis D., Petrotos K., I. Giavasis, "The effect of encapsulated powder of goji berry (Lycium barbarum) on growth and survival of probiotic bacteria,” Microorganisms, vol. 28, no. 8(1), pp. 57, 2019. DOI: $10.3390 /$ microorganisms8010057

[34] Dixon R.A. "Natural products and plant disease resistance," Nature, vol. 411, pp. 843-847, 2001. DOI: $10.1038 / 35081178$

[35] Oksman-Caldentey K.M., D. Inze, "Plant cell factories in the post-genomic era: new ways to produce designer secondary metabolites,” Trends in Plant Science, vol. 9, no. 9, pp. 433-440, 2004. DOI: 10.1016/j.tplants.2004.07.006

[36] Wink M. "Plant secondary metabolism: diversity, function and its evolution," Natural Products Community, vol. 3, pp. 1205-1216, 2008. DOI: 10.1177/1934578X0800300801

[37] Scorzoni L., Sangalli-Leite F., de Lacorte Singulani J., de Paula e Silva A.C.A., Costa- Orlandi C.B., Fusco-Almeida A.M., M.J.S. Mendes-Giannini, "Searching new antifungals: The use of in vitro and in vivo methods for evaluation of natural compounds," Journal of Microbiological Methods, vol. 123, pp. 68-78, 2016. DOI: 10.1016/j.mimet.2016.02.0 05

[38] Skenderidis P., Mitsagga C., Giavasis I., Hadjichristodoulou C., Leontopoulos S., Petrotos K., A. Tsakalof, “Assessment of antimicrobial properties of aqueous UAE extracts of goji berry fruit and pomegranate fruit peels in vitro," Proceeding of International Conference on Food and Biosystems Engineering, 01-04 June 2017, Rhodes island, 538-546, 2017.

[39] Skenderidis P., Petrotos K., Giavasis I., Hadjichristodoulou, C., A. Tsakalof, "Optimization of ultrasound assisted extraction of goji berry (Lycium barbarum) fruits and evaluation of extracts' bioactivity,” Journal of Food Process Engineering, vol. 40, no. 5, pp. 12522, 2017. DOI: $10.1111 /$ jfpe. 12522

[40] Leontopoulos S., Skenderidis P., Kalorizou H., K. Petrotos, "Bioactivity potential of polyphenolic compounds in human health and their effectiveness against various food bome and plant pathogens. A review," International Journal of Food and Biosystems Engineering, vol. 7, no. 1, pp.1-19, 2017.

[41] Zaynab M., Fatima M., Abbas, S., Sharif, Y., Umair, M., Hammad Zafare, M., K. Bahadar, "Role of secondary metabolites in plant defense against pathogens,” Microbial Pathology, vol. 124, pp. 198-202, 2018. DOI: 10.1016/j.micpath.2018.08.034 
220 Potential Synergistic Action of Liquid Olive Fruit Polyphenol Extract with Aqueous Extracts of Solid Wastes of Pomegranate or/and Orange Juice Industry as Organic Phyto-protective Agents against Important Plant Pathogens - Part 1 (in vitro Studies)

[42] Chavez J.H., Leal P.C., Yunes R.A., Nunes R.J., Barardi C.R., Pinto A.R., Simoes C.M., C.R. Zanetti, “Evaluation of antiviral activity of phenolic compounds and derivatives against rabies virus," Veterinary Microbiology, vol. 116, pp. 53-59, 2006. DOI: 10.1016/j.vetmic.2006.03.019

[43] Abd-El-Kareem, F. "Induced resistance in bean plants against root tot and alternaria leaf spot diseases using biotic and abiotic inducers under field conditions,” Residue Journal of Agriculture Biology Science, vol. 3, no. 6, pp. 767-774, 2007.

[44] Mierziak J., Kostyn K., A. Kulm, "Flavonoids as important molecules of plant interactions with the environment," Molecules, vol. 19, pp. 16240-16265, 2014. DOI: 10.3390/molecules191016240

[45] González-Lamothe R., Mitchell G., Gattuso M., Diarra M.S., Malouin F., K. Bouarab, "Plant antimicrobial agents and their effects on plant and human pathogens," International Journal of Molecular Science, vol. 10, pp. 3400-3419, 2009. DOI: $10.3390 /$ ijms10083400

[46] Ani V., Varadaraj M.C., A.K. Naidu, “Antioxidant and antibacterial activities of polyphenolic compounds from bitter cumin (Cuminum nigrum L.)," European Food Residue Technology, vol. 224, pp. 109-115, 2006. DOI: 10.1007/s00217-006-0295-Z

[47] Okoro I.O., Osagie A., E.O. Asibor, "Antioxidant and antimicrobial activities of polyphenols from ethnomedicinal plants of Nigeria,” African Journal of. Biotechnology, vol. 9, no. 20, pp. 2989-2993, 2010.

[48] Brimner T.A., G.J. Boland, "A review of the non-target effect of fungi used to biologically control plant diseases," Agricultural Ecosystem Environment, vol. 100, pp. 3-16, 2003. DOI: 10.1016/S0167-8809(03)00200-7

[49] Bruno G., L. Sparapano, "Effects of three esca-associated fungi on Vitis vinifera L:V. Changes in the chemical and biological profile of xylem sap from diseased cv. Sangiovese vines,” Physiology and Molecular Plant Pathology, vol. 71, pp. 210-229, 2007. DOI: 10.1016/j.pmpp.2008.02.005

[50] Leontopoulos S., Skenderidis P., Anatolioti V., Kokkora M., Tsilfoglou S., Petrotos K., I. Vagelas, “Antifungal activity of Azadirachta indica aqueous and non-aqueous extracts on Colletotrichum gloeosporioides, Botryodiplodia theobromae and Fusarium solani. A first approach," International Journal of Food and Biosystems Engineering, vol. 6, no. 1, pp. 38-50, 2017.

[51] Skenderidis P., Kerasioti E., Karkanta E., Stagos D., Kouretas D., Petrotos K., Hadjichristodoulou C., A. Tsakalof, "Assessment of the antioxidant and antimutagenic activity of extracts from goji berry of Greek cultivation,” Toxicology Reports, vol. 5, pp. 251-257, 2018. DOI: 10.1016/j.toxrep.2018.02.001

[52] Silva V., Mol H.G.J., Zomer P., Tienstra M., Ritsema C.J., V. Geissen, "Pesticide residues in European agricultural soilsA hidden reality unfolded," Science of Total Environment, vol. 653, pp. 1532-1545, 2019. DOI: 10.1016/j.scitotenv.2018.10.441

[53] Chawla P., Kaushika R., Swaraj V.J.S., N. Kumar, "Organophosphorus pesticides residues in food and their colorimetric detection,” Environmental Nanotechnology and Monitoring Management, vol. 10, pp. 292-307, 2010. DOI:

\subsection{6/j.enmm.2018.07.013}

[54] Kumari D., S. John, "Health risk assessment of pesticide residues in fruits and vegetables from farms and markets of western Indian Himalayan region," Chemosphere, vol. 224, pp. 162-167, 2019. DOI: 10.1016/j.chemosphere.2019.02.0 91

[55] MacLoughlin T.M., Peluso L., Etchegoyen A., Alonso L.L., de Castro C., Percudani C., D.J.G. Marino, "Pesticide residues in fruits and vegetables of the Argentine domestic market: Occurrence and quality,” Food Control, vol. 93, pp. 129-138, 2018. DOI: 10.1016/j.foodcont.2018.05.041

[56] Tang W., Wang D., Wang J., Wu Z., Li L., Huang M., Xu S., D. Yan, "Pyrethroid pesticide residues in the global environment: An overview," Chemosphere, vol. 191, pp. 990-1007, 2018. DOI: 10.1016/j.chemosphere.2017.10.115

[57] Ma S., Ji R., Wang X., Yu C., Yu Y., X. Yang, "Fluorescence detection of boscalid pesticide residues in grape juice,” Optik, International Journal of Light Electron Optics, vol. 180, pp. 236-239, 2019. DOI: 10.1016/j.ijleo.2018.11.106

[58] Zervas, N. "The European eco label. Law and nature", http://www.nomosphysis.org.gr/index.php (assessed March, 3, 2020).

[59] Balk C., Chatzipavlidis J., F. Flouri, "Olive mill waste as a substrate for Nitrogen fixation,” International Biology and Biodegradation, pp. 169-118, 1996. DOI: 10.1016/S0964-8 305(96)00047-9

[60] Beccardi M., Bonemazzi F., Majone M., C. Riccardi, "Interaction between acidogenesis and metahnogenesis in anaerobic treatment of olive mill effluents,” Water Residues, vol. 30, pp. 83-189, 1996. DOI: 10.1016/0043-1354(95)000 86-Z

[61] Ryan D., K. Robards, "Phenolic compounds in olives," Analyst, vol. 123, pp. 31-44, 1998.

[62] Bisignano G., Tomaino A., Lo Cascio R., Crisafi G., N. Uccela, "On the in-vitro antimicrobial activity of oleuropein and hydroxytyrosol,” Journal of Pharmacology, vol. 51, pp. 971-974, 1999. DOI: 10.1211/0022357991773258

[63] Paredes C., Cegarra J., Roig A., Sfinchez-Monedero M.A., M.P. Bernal, "Characterization of olive mill wastewater (alpechin) and its sludge for agricultural purposes," Bioresource Technology, vol. 67, pp. 111-115, 1999. DOI: 10.1016/S0960-8524(98)00106-0

[64] Kotsou M., Mari I., Lasaridi K., Chatzipavlidis I., Balis C., A. Kyriacou, “The effect of olive oil mill wastewater (OMW) on soil microbial communities and suppressiveness against Rhizoctonia solani,” Applied Soil Ecology, vol. 26, pp. 113-121, 2004. DOI: 10.1016/j.apsoil.2003.12.001

[65] Bonanomi G., Giorgi V., Del Sorbo G., Neri D., F. Scala, "Olive mill residues affect saprophytic growth and disease incidence of foliar and soilborne plant fungal pathogens," Agricultural Ecosystem Environment, vol. 115, pp. 194-200, 2006. DOI: 10.1016/j.agee.2006.01.002

[66] Mehrgan H., Mojab F., Pakdaman, S., M. Poursaeed, "Antibacterial activity of Thymus pubescens methanolic extract,” Iranian Journal of Pharmacology Residues, vol. 87, no. 4, pp. 291-295, 2000. DOI: 10.22037/ijpr.2010.778 
[67] Liu H.M., Guo J.H., Cheng Y.J., Liu P., Long C.A., B.X. Deng, "Inhibitory activity of tea polyphenol and Hanseniaspora uvarum against Botrytis cinerea infections," Letters in Applied Microbiology, vol. 51, pp. 258-263, 2010. DOI: 10.1111/j.1472-765X.2010.02888.X

[68] Xia E., Deng G., Guo Y., H. Li, "Biological activities of polyphenols from grapes," International Journal of Molecular Science, vol. 11, pp. 622-646, 2010. DOI: 10.3390/ijms11020622

[69] Leontopoulos S.V., Giavasis I., Petrotos K., Kokkora M., Ch. Makridis, "Effect of different formulations of polyphenolic compounds obtained from OMWW on the growth of several fungal plant and food borne pathogens. Studies in vitro and in vivo," Agriculture and Agricultural Science Procedia, vol. 4, pp. 327-337, 2015. DOI: 10.1016/j.aaspro.2015.03.037

[70] Kokkora M.I., Petrotos K.B., Papaioannou Ch., Gkoutsidis P.E., Leontopoulos S.V., P. Vyrlas, "Agronomic and economic implications of using treated olive mill wastewater in maize production,” Desalination and Water Treatment, pp. 1-7, 2016. DOI: 10.1080/19443994.2016.11 53905

[71] Petrotos K.B., Kokkora M.I., Gkoutsidis P.E., S. Leontopoulos, "A comprehensive study on the kinetics of Olive Mill wastewater (OMWW) polyphenols absorption on macroporous resins. Part II. The case of Amperlite FPX66 commercial resin," Desalination and Water Treatment, pp. 1-8, 2016. DOI: 10.1080/19443994.2015.11 11820

[72] Petrotos K., Lampakis D., Pilidis G., S.V. Leontopoulos, "Production and encapsulation of polyphenols derived from clarifies waste by using a combination of macroporous resins and spray drying,” International Journal of Food and Biosystems Engineering, vol. 1, no. 1, pp. 40-50, 2016.

[73] Leontopoulos S.V., Kokkora M.I., K.B. Petrotos, "In vivo evaluation of liquid polyphenols obtained from OMWW as natural bio-chemicals against several fungal pathogens on tomato plants," Desalination and Water Treatment, pp. 1-15, 2016. DOI: 10.1080/19443994.2016.1154707

[74] Singh M., Singh D., Gupta A., Pandey K.D., Singh P.K., A. Kumar, "Plant growth promoting rhizobacteria: Application in biofertilizers and biocontrol of phytopathogens," PGPR Amelioration in Sustainable Agriculture, Food Security and Environmental Management, pp. 41-66, 2019. DOI: 10.1016/B978-0-12-815879-1.00003-3

[75] Mhatre S.V., Bhagit A.A., R.P. Yadav, "Proteinaceous pancreatic lipase inhibitor from the seed of Litchi chinensis," Food Technology and Biotechnology, vol. 57, no. 1, pp. 113-118, 2019. DOI: 10.17113/ftb.57.01.19.5909

[76] Thakur M., Bhattacharya S., Kumar P., K.S. Puri, "Improving production of plant secondary metabolites through biotic and abiotic elicitation,” Journal of Applied Research Mediterranean Aromatic Plants, vol. 12, pp. 1-12, 2019. DOI: 10.1016/j.jarmap.2018.11.004

[77] Vagelas I., S. Leontopoulos, "Cross-protection of cotton against Verticillium wilt by Verticillium nigrescens," Emirates Journal of Food Agriculture, vol. 27, no 9, pp. 687-691, 2015. DOI: 10.9755/ejfa.2015-04-047

[78] Ganusova E.E., T.M. Burch-Smith, "Review:
Plant-pathogen interactions through the plasmodesma prism," Plant Science, vol. 279m pp. 70-80, 2019. DOI: 10.1016/j.plantsci.2018.05.017

[79] Munoz I.V., Sarrocco S., Malfatti L., Baroncelli R., G. Vannacci, "CRISPR-Cas for fungal genome Editing: A New tool for the management of plant diseases," Frontiers in Plant Science, vol. 10, pp. 1-5, 2019. DOI: 10.3389/fpls.2019.001 35

[80] Malik A., Afaq F., Sarfaraz S., Adhami V.M., Seyed D.N., H, Mukhtar, "Pomegranate fruit juice for chemoprevention and chemotherapy of prostate cancer," Procedia of National Academic Science, vol. 102, pp. 14813-14818, 2005. DOI: 10.1073/pnas.0505870102

[81] Dey D., Debnath S., Hazra S., Ghosh S., Ray R., B. Hazra, "Pomegranate pericarp extract enhances the antibacterial activity of ciprofloxacin against extended-spectrum b-lactamase (ESBL) and metallo-b-lactamase (MBL) producing gram-negative bacilli," Food Chemistry and Toxicology, vol. 50, pp. 4302-4309, 2012. DOI: 10.1016/j.fct.2012.09.001

[82] Kalaycioglu Z., F.B. Erim, "Total phenolic contents, antioxidant activities, and bioactive ingredients of juices from pomegranate cultivars worldwide,” Food Chemistry, vol. 221, pp. 496-507, 2017. DOI: 10.1016/j.foodchem.201 6.10 .084

[83] Skenderidis P., Mitsagga C., Giavasis I., Petrotos K., Lampakis D., Leontopoulos S., Hadjichristodoulou C., A. Tsakalof, "The in vitro antimicrobial activity assessment of ultrasound assisted Lycium barbarum fruit extracts and pomegranate fruit peels," Journal of Food Measurement and Characterization, pp. 1-15, 2019. DOI: 10.1007/s11694-019 $-00123-6$

[84] Endo E.H., Cortez D.A.G., Ueda-Nakamura T., Nakamura C.V., B.P.D. Filho, "Potent antifungal activity of extracts and pure compound isolated from pomegranate peels and synergism with fluconazole against Candida albicans," Residual Microbiology, vol. 161, pp. 534-540, 2010. DOI: 10.1016/j.resmic.2010.05.002

[85] Braga L., Leite A.A.M., Xavier K.G.S., Takahashi J., Bemquerer M.P., Chartone-Souza E., A.M.A. Nascimento, "Synergic interaction between pomegranate extract and antibiotics against Staphylococcus aureus," Canadian Journal of Microbiology, vol. 51, no. 7, pp. 541-547, 2005. DOI: $10.1139 /$ w05-022

[86] Reddy, B.N., C.R. Raghavender, "Outbreaks of aflatoxicoses in India,” African Journal of Food Agriculture and Nutrition, vol. 7, pp. 1-15, 2007.

[87] Reddy C.S., Reddy K.R.N., Prameela M., Mangala U.N., K. Muralidharan, "Identification of antifungal component in clove that inhibits Aspergillus spp. colonizing rice grains," Journal of Mycology and Plant Pathology, vol. 37, pp. 87-94, 2007.

[88] Reddy K.R.N., Reddy C.S., K. Muralidharan, "Exploration of ochratoxin a contamination and its management in rice," American Journal of Plant Physiology, vol. 2, pp. 206-213, 2007. DOI: 10.3923/ajpp.2007.206.213

[89] Reddy K.R.N., Nurdijati S.B., B. Salleh, “An overview of plant-derived products on control of mycotoxigenic fungi and mycotoxins,” Asian Journal of Plant Science, vol. 9, no. 
222 Potential Synergistic Action of Liquid Olive Fruit Polyphenol Extract with Aqueous Extracts of Solid Wastes of Pomegranate or/and Orange Juice Industry as Organic Phyto-protective Agents against Important Plant Pathogens - Part 1 (in vitro Studies)

3, pp. 126-133, 2010. DOI: 10.3923/ajps.2010.126.133

[90] Al-Zoreky N.S. “Antimicrobial activity of pomegranate (Punica granatum L.) fruit peels,” International Journal of Food Microbiology, vol. 134, pp. 244-248, 2009. DOI: 10.1016/j.ijfoodmicro.2009.07.002

[91] Vagelas I., Papachatzis A., Kalorizou H., E. Wogiatzi, "Biological control of Botrytis fruit rot (gray mold) on strawberry and red pepper fruits by olive oil mill wastewater," Biotechnology Biotechnological Equipments, vol. 23, no. 4, pp. 1489-1491, 2009. DOI: 10.2478/V10133-009-0017-3

[92] Vagelas I., Kalorizou H., Papachatzis A., M. Botu, "Bioactivity of olive oil mill wastewater against plant pathogens and post-harvest diseases", Biotechnology and Biotechnological Equipments , vol. 23, no. 2, pp. 1217-1219, 2011. DOI: $10.1080 / 13102818.2009 .10817641$
[93] Lykas C., Vagelas I., N. Gougoulias, "Effect of olive mill wastewater on growth and bulb production of tulip plants infected by bulb diseases,” Spanish Journal of Agricultural Residues, vol. 12, pp. 233, 2014. DOI: 10.5424/sjar/201412 $1-4662$

[94] Yangui T., Rhouma A., Triki M.A., Gargouri K., J. Bouzid, "Control of damping-off caused by Rhizoctonia solani and Fusarium solani using olive mill waste water and some of its indigenous bacterial strains," Crop Protection, vol. 27, pp. 189-197, 2008. DOI: 10.1016/j.cropro.2007.05.005

[95] Mavrakis, N. "Exploitation of bioactive constituents of olive leaves, grape pomace, olive mill waste water and their application in phytoprotection” Ph.D THESIS, Cranfield University, 2009. http://hdl.handle.net/1826/4494 (Assessed on March, 5, 2020). 